\title{
Proteogenomic Insights into the Physiology of Marine, Sulfate-Reducing, Filamentous Desulfonema limicola and Desulfonema magnum
}

\author{
Vanessa Schnaars $^{a}$ Lars Wöhlbrand ${ }^{a}$ Sabine Scheve ${ }^{a}$ Christina Hinrichs $^{\text {a }}$ \\ Richard Reinhardt ${ }^{b}$ Ralf Rabus ${ }^{a}$
}

a General and Molecular Microbiology, Institute for Chemistry and Biology of the Marine Environment (ICBM), Carl von Ossietzky University of Oldenburg, Oldenburg, Germany; ${ }^{b}$ Max-Planck-Genome-Centre Cologne, Max Planck Institute for Plant Breeding Research, Cologne, Germany

\section{Keywords}

Complete genome - Differential proteomics - Metabolism . Anaerobic degradation - Aromatic compounds · Sulfate reduction · Physiology · Stress response - Desulfonema limicola $\cdot$ Desulfonema magnum

\begin{abstract}
The genus Desulfonema belongs to the deltaproteobacterial family Desulfobacteraceae and comprises marine, sulfate-reducing bacteria that form filaments and move by gliding. This study reports on the complete, manually annotated genomes of Dn. limicola 5ac10 $10^{\top}$ (6.91 Mbp; 6,207 CDS) and Dn. magnum 4 be $13^{\top}$ (8.03 Mbp; 9,970 CDS), integrated with substrate-specific proteome profiles (8 vs. 11). The richness in mobile genetic elements is shared with other Desulfobacteraceae members, corroborating horizontal gene transfer as major driver in shaping the genomes of this family. The catabolic networks of Dn. limicola and Dn. magnum have the following general characteristics: 98 versus 145 genes assigned (having genomic shares of 1.7 vs. $2.2 \%$ ), 92.5 versus $89.7 \%$ proteomic coverage, and scattered gene clusters for substrate degradation and energy metabolism. The Dn. magnum typifying capacity for aromatic compound degradation (e.g., p-cresol, 3-phenylpropionate) requires 48 genes organized in operon-like structures (87.7\% proteomic coverage; no homologs in Dn. limicola). The protein complements for aliphatic
\end{abstract}

karger@karger.com www.karger.com/mip

Karger $\frac{1}{6}$
C 2021 The Author(s)

Published by S. Karger AG, Basel

This is an Open Access article licensed under the Creative Commons Attribution-NonCommercial-4.0 International License (CC BY-NC) (http://www.karger.com/Services/OpenAccessLicense), applicable to the online version of the article only. Usage and distribution for commercial purposes requires written permission. compound degradation, central pathways, and energy metabolism are highly similar between both genomes and were identified to a large extent (69-96\%). The differential protein profiles revealed a high degree of substrate-specificity for peripheral reaction sequences (forming central intermediates), agreeing with the high number of sensory/regulatory proteins predicted for both strains. By contrast, central pathways and modules of the energy metabolism were constitutively formed under the tested substrate conditions. In accord with their natural habitats that are subject to fluctuating changes of physicochemical parameters, both Desulfonema strains are well equipped to cope with various stress conditions. Next to superoxide dismutase and catalase also desulfoferredoxin and rubredoxin oxidoreductase are formed to counter exposure to molecular oxygen. A variety of proteases and chaperones were detected that function in maintaining cellular homeostasis upon heat or cold shock. Furthermore, glycine betaine/proline betaine transport systems can respond to hyperosmotic stress. Gliding movement probably relies on twitching motility via type-IV pili or adventurous motility. Taken together, this proteogenomic study demonstrates the adaptability of Dn. limicola and Dn. magnum to its dynamic habitats by means of flexible catabolism and extensive stress response capacities.

(C) 2021 The Author(s)

Published by S. Karger AG, Basel

Dedicated to Fritz Widdel who discovered Desulfonema. 


\section{Introduction}

Dissimilatory sulfate-reducing bacteria (SRB) couple the oxidation of organic molecules to the reduction of sulfate $\left(\mathrm{SO}_{4}{ }^{2-}\right)$ to sulfide $\left(\mathrm{S}^{2-}\right)$ and resume diverse functions in ecology, health, and biotechnology [Widdel, 1988; Muyzer and Stams, 2008; Rabus et al., 2015]. The high concentration of sulfate $(28 \mathrm{mM})$ in ocean waters facilitates a central role of SRB in the oxidation of organic matter in anoxic marine sediments and thereby in the global cycles of carbon and sulfur [Jørgensen, 1982; Canfield et al., 1993; Bowles et al., 2014]. These process contributions are mainly performed by the completely oxidizing (to $\mathrm{CO}_{2}$ ) and nutritionally versatile members of the deltaproteobacterial family Desulfobacteraceae [Fenchel and Jørgensen, 1977; Devereux et al., 1989; Küver, 2014]. To elucidate the molecular basis of this important SRB family, several metabolically/ecologically relevant members have been subjected to genomic and differential proteomic analyses in our group: the facultative chemolithoautotrophic Desulfobacterium autotrophicum HRM2 [Strittmatter et al., 2009; Amann et al., 2010; Dörries et al., 2016b], the aromatic compound-degrading Desulfobacula toluolica Tol2 [Wöhlbrand et al., 2013, 2016], and the versatile Desulfococcus multivorans DSM 2059 [Dörries et al., 2016a].

Morphologically outstanding within the family Desulfobacteraceae is the genus Desulfonema, which harbors filamentous SRB performing gliding movement. This genus was discovered by Fritz Widdel in the early 1980s by developing specific procedures for enriching and isolating filamentous bacteria [Widdel, 1983]. These new approaches rendered possible the isolation of Desulfonema limicola $5 \mathrm{ac} 10^{\mathrm{T}}$ from the mud flat of the Jadebusen (Germany) and Desulfonema magnum 4 be $13^{\mathrm{T}}$ from anaerobic sediment of a sea water lagoon (Southern France) [Widdel et al., 1983]. By comparison, Dn. limicola has somewhat smaller cells and is capable of chemolithoautotrophy, while Dn. magnum forms larger cells/longer filaments, utilizes aromatic compounds and accumulates large amounts of poly(3-hydroxybutyrate) during anaerobic growth with benzoate [Widdel et al., 1983; Hai et al., 2004]. Dn. ishimotonii Tokyo $01^{\mathrm{T}}$ was isolated from marine sediment of Tokyo Bay (Japan) and shows nutritional similarity to Dn. limicola [Fukui et al., 1999]; its recently determined genome ( 9 contigs) also revealed extensive impact of horizontal gene transfer [Watanabe et al., 2019]. Phylotypes of Desulfonema spp. were detected in microbial mats of geographically distant regions: Solar Lake (Sinai, Egypt) [Teske et al., 1998; Minz et al., 1999], Camar- gue (France) [Fourçans et al., 2008], Shark Bay (Western Australia) [Wong et al., 2015], and Zodletone spring (OK, USA) [Elshahed et al., 2003]. Furthermore, Desulfonema phylotypes have been observed in sheaths of marine, nitrate-reducing, sulphur-oxidizing Thioploca spp. on the Chilean continental shelf [Teske et al., 2009], in the seagrass root microbiome from the Leschenault Estuary (Bunbury, Western Australia) [Martin et al., 2020], as well as in rice roots (Vercelli, Italy) [Scheid and Stubner, 2001]. These reports on isolates and phylotypes demonstrate the broad geographic distribution of Desulfonema spp. and indicate an adaptation to dynamic gradient systems, including anoxic-oxic transitions.

The aims of the present study were (i) to provide complete, manually annotated genomes of two representatives of the genus Desulfonema, namely Dn. limicola and Dn. magnum, and thus of further members of the family Desulfobacteraceae, (ii) to compare their predicted metabolic potentials by integrating differential proteomic profiles of substrate-adapted cells, and (iii) to explore the proteogenomic imprint of their specific lifestyles.

\section{Results and Discussion}

\section{General Genome Features}

With sizes of $6.91 \mathrm{Mbp}$ and $8.03 \mathrm{Mbp}$, respectively, the genomes of Dn. limicola $5 \mathrm{ac} 10^{\mathrm{T}}$ and Dn. magnum 4 be $13^{\mathrm{T}}$, like that of recently reported $\mathrm{Dn}$. ishimotonii Tokyo $01^{\mathrm{T}}$ (6.64 Mbp contig assembly) [Watanabe et al., 2019], are considerably larger than those of other Desulfobacteraceae members, ranging between $4.46 \mathrm{Mbp}(D c$. multivorans) [Dörries et al., 2016a] and 5.59 Mbp (Dt. autotrophicum) [Strittmatter et al., 2009], and by far exceed those of incompletely oxidizing (to acetate) members of the family Desulfovibrionaceae (e.g., 3.77 Mbp for Desulfovibrio vulgaris Hildenborough [Heidelberg et al., 2004]). Figure 1 provides a graphical overview of the circular genomes of Dn. limicola and Dn. magnum, high-

Fig. 1. Structural representation of the circular chromosomes of Desulfonema limicola $5 \mathrm{a} 10^{\mathrm{T}}$ (top) and Desulfonema magnum 4 be $13^{\mathrm{T}}$ (bottom). The insert defines the color coding of rings for the selected functions. The scale $(\mathrm{Mbp})$ is indicated by the outer ring. Chemical structures of growth supporting aromatic and aliphatic compounds are presented at the outside. Compound numbering is as follows: 1,4 -hydroxybenzoate; 2 , benzoate; 3 , $p$-cresol; 4 , 3 -phenylpropionate; 5 , phenylacetate; $6, n$-propanol; 7 , propionate; 8 , succinate; 9 , fumarate; 10 , malate; 11 , lactate; 12 , butyrate; 13 , valerate; 14 , acetate; 15 , carbon dioxide.

(For figure see next page.) 


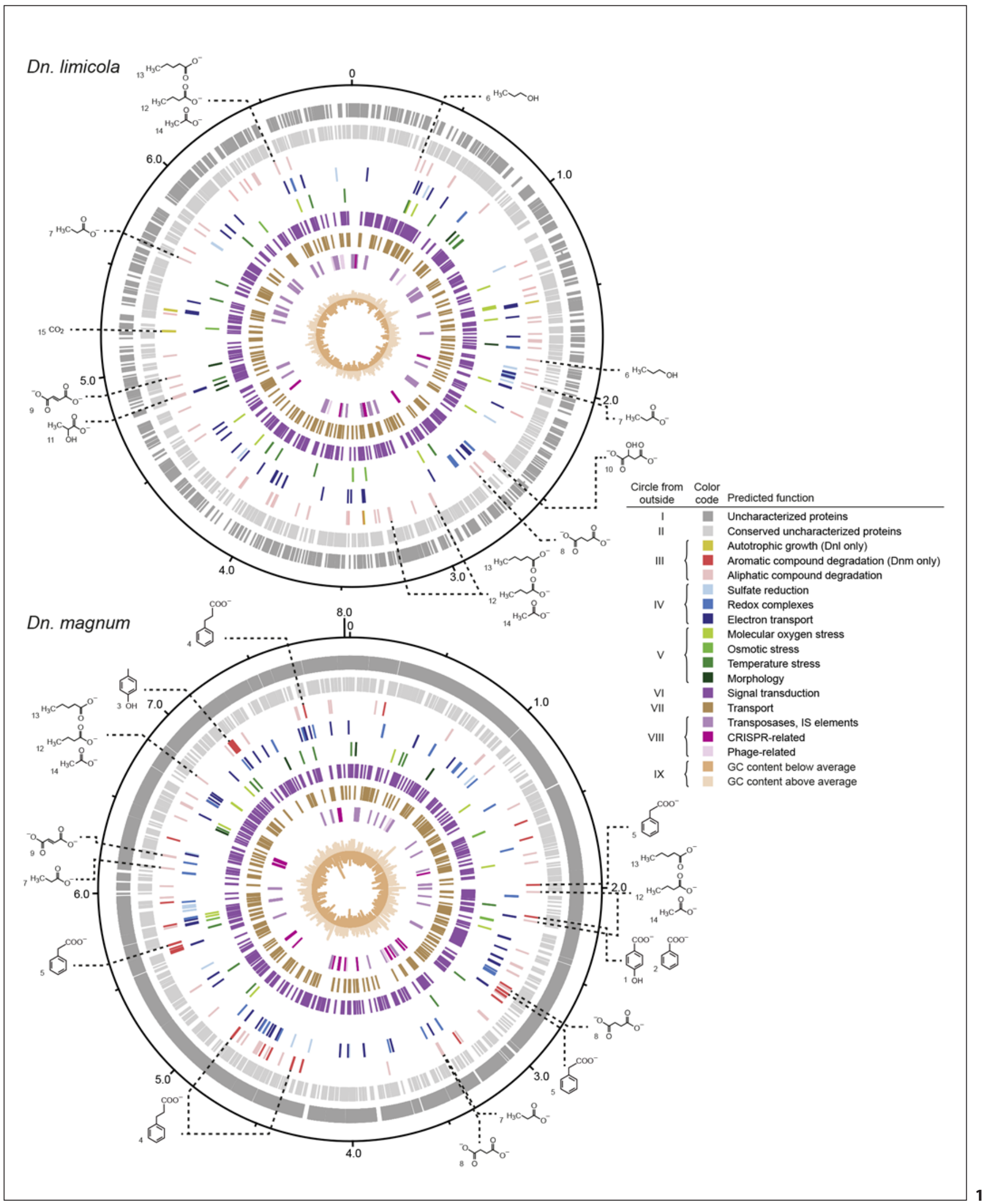


Table 1. General genome features

\begin{tabular}{|c|c|c|c|c|c|c|}
\hline Genome features & $\begin{array}{l}\text { Desulfonema } \\
\text { limicola } \\
5 \mathrm{ac} 10^{\mathrm{T}}\end{array}$ & $\begin{array}{l}\text { Desulfonema } \\
\text { magnum } \\
4 \mathrm{be} 13^{\mathrm{T}}\end{array}$ & $\begin{array}{l}\text { Desulfonema } \\
\text { ishimotonii } \\
\text { Tokyo } 01^{\mathrm{Ta}}\end{array}$ & 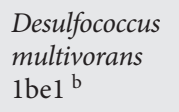 & $\begin{array}{l}\text { Desulfobacula } \\
\text { toluolica } \\
\text { Tol2 } 2^{\mathrm{Tc}}\end{array}$ & $\begin{array}{l}\text { Desulfobacterium } \\
\text { autotrophicum } \\
\text { HRM2 }{ }^{\mathrm{d}}\end{array}$ \\
\hline Sequencing status & complete & complete & 9 contigs & complete & complete & complete \\
\hline $\mathrm{G}+\mathrm{C}$ content, $\mathrm{mol} \%$ & 39 & 45 & 68 & 57 & 42 & 49 \\
\hline rRNA operons & 2 & 1 & 4 & 3 & 4 & 6 \\
\hline Coding, $\%$ & 89.9 & 86.9 & 79 & 87 & 87 & 88 \\
\hline Average size, bp & 1,001 & 700 & nd & 985 & 1,039 & 1,017 \\
\hline Assigned function & 3,929 & 4,015 & 3,724 & 2,648 & 3,188 & 3,477 \\
\hline Conserved unknown & 1,173 & 1,121 & $1,273^{\mathrm{e}}$ & 689 & 681 & 1,466 \\
\hline Unknown & 1,105 & 4,834 & nd & 605 & 512 & nd \\
\hline Plasmids & - & - & nd & - & - & 1 \\
\hline
\end{tabular}

a Data taken from Watanabe et al. [2019]. ${ }^{b}$ Data taken from Dörries et al. [2016a]. ${ }^{\mathrm{c}}$ Data taken from Wöhlbrand et al. [2013]. ${ }^{\mathrm{d}}$ Data

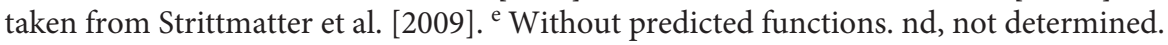

lighting the respective genetic repertoires for metabolism and mobilome. General genome features are given and compared to other members of the family Desulfobacteraceae in Table 1. Interestingly, although the genomes of Dn. limicola and Dn. ishimotonii Tokyo $01^{\mathrm{T}}$ are of rather similar size (differing by $0.25 \mathrm{Mbp}$ ), that of Dn. limicola possesses more protein-coding sequences (CDS). Furthermore, the GC content of strain Tokyo $01^{\mathrm{T}}$ is pronouncedly higher $(68 \%)$ as compared to the other Desulfonema species (39 and 45\%) and Desulfobacteraceae members (42-57\%).

A remarkable feature of the large Dn. magnum genome is the very high portion of genes $(59.7 \%$ of all CDS) encoding proteins of (conserved) unknown function that cumulatively account for $\sim 30 \%$ of the genome sequence (Fig. 1; Table 1). Likewise, the genome of Dn. limicola codes for a high portion of proteins of unknown function (36.7\%) as compared to the other Desulfobacteraceae members $(<32.8 \%)$, Dv. vulgaris Hildenborough (33.9\%), Geobacter sulfurreducens PCA (27.3\%), or Escherichia coli K12 (14.3\%). Thus, one may speculate that some of these genes are the basis for so far unknown properties specific to Desulfonema spp. Indeed, 319 proteins of unknown function (including paralogs) are homologous in Dn. limicola and Dn. magnum (applying $>50 \%$ identity and covering $>50 \%$ of sequence length).
Furthermore, 280 homologous proteins of unknown function are also encoded in Dn. ishimotonii (in total 1,273 ), while only $<169$ are present in the other Desulfobacteraceae members, supporting this hypothesis. Acquisition and/or evolution of these genes may have been facilitated by the high number of transposases and ISelements that account for 3.5\% of all CDS in Dn. magnum (similar to $3.7 \%$ in Db. toluolica Tol2) and even $11.3 \%$ in Dn. limicola (only $0.9 \%$ in Dv. vulgaris Hildenborough and $1.2 \%$ in both G. sulfurreducens PCA and E. coli K12). Some of these mobile genetic elements are constituents of genomic islands and islets (20/6 and 12/15 for Dn. limicola and Dn. magnum, respectively). Furthermore, the presence of prophages in the chromosome as well as several CRISPR/Cas loci (8 and 20 for Dn. limicola and Dn. magnum, respectively) indicate severe phage impact on the genomes of both strains [Horvath and Barrangou, 2010]. Overall, the apparent high genome plasticity mediated by the large number of mobile genetic elements and, hence, facilitating horizontal gene transfer [Oliveira et al., 2017], does not only appear as an overarching property among to date determined genomes of Desulfobacteraceae members, but may also have been particularly instrumental for expansion of the two studied Desulfonema genomes. 
To compare the relevance of clusters of orthologous genes (COGs) between the two studied Desulfonema strains, the genomic shares (i.e., portion of total coding sequence) captured by the CDS assigned to each COG category were determined (Fig. 2a; online suppl. Table S1; see www.karger.com/doi/10.1159/000513383 for all online suppl. material). Despite rather similar profiles of the relative shares of COG categories (designations are specified in the legend to Fig. 2) in both strains, several differences were noted: in Dn. limicola, a higher portion (difference $>0.4$ percentage points) in genes of transcription $(\mathrm{K})$, replication, recombination and repair $(\mathrm{L})$, signal transduction $(\mathrm{T})$, defense $(\mathrm{V})$, energy production and conversion (C), lipid transport and metabolism (I), and inorganic ion transport and metabolism (P) was observed. By contrast, Dn. magnum revealed higher shares in cell wall/membrane/envelope biogenesis (M), posttranslational modification, protein turnover and chaperons $(\mathrm{O})$, intracellular trafficking and secretion (U) and most pronounced in genes not assigned to a COG category $(\mathrm{NiC})$.

\section{Proteomic Dataset and Coverage}

Differential proteomic analyses of Dn. limicola and Dn. magnum were based on 3 types of substrate adaptation conditions: (i) shared by both strains (butyrate, propionate, fatty acids mixture, succinate, and fumarate); (ii) specific for Dn. limicola $\left(\mathrm{H}_{2} / \mathrm{CO}_{2}, n\right.$-propanol, lactate), and (iii) specific for Dn. magnum (malate, benzoate, phenylacetate, 3-phenylpropionate, p-cresol, and 4-hydroxybenzoate). Biological replicate samples of each growth condition were analyzed with respect to the composition of the soluble as well as the membrane proteinenriched fractions. Overall, 1,133 and 1,413 nonredundant proteins were identified for Dn. limicola and Dn. magnum, corresponding to a total proteomic coverage of 18.3 and $26.1 \%$, respectively.

Interestingly, while the genomic share of most COG categories was higher in Dn. limicola as compared to Dn. magnum ( 15 out of $27,>0.05 \%$ points difference, 5 for $D n$. magnum), the situation is reversed in case of protein formation (Fig. 2a; online suppl. Table S2). Here, only in 4 categories a higher proportion was detected for Dn. limicola, while in 14 categories Dn. magnum accounted for a larger share. Most pronounced is this difference for genes related to cellular structure $(\mathrm{M})$, coenzyme metabolism $(\mathrm{H})$, secondary metabolites $(\mathrm{Q})$, and proteins not assigned (NiC). Furthermore, for a number of categories (J, K, L, T, C, E, G, H, P, and S), the formed protein complement of Dn. magnum exceeds that of Dn. limicola, although the latter disposes of the larger genomic potential. This difference, however, may also be due to metabolism of aromatic compounds by Dn. magnum necessitating a suite of other, non-catabolic proteins (e.g., for detoxification) not required under the conditions tested with Dn. limicola. Apparently, both strains share a similar minimum with respect to the use of their genomic potential (protein formed vs. predicted only) of at least 6.8 and $8.3 \%$ in case of category L. In contrast, the maximum use is smaller in case of Dn. limicola (49.2\%, category I) than in Dn. magnum (61.2\%, category C), and Dn. magnum apparently in general employs more of its genome encoded proteins (on average 32.4 vs. $26.0 \%$ for Dn. limicola), being consistent with the above described observations.

To assess similarities between the different growth conditions per studied Desulfonema strain, principle component analysis was applied, using the portion of proteins detected of the genomic potential per COG category (Fig. $2 \mathrm{~b}$ top and center). For both organisms, the different growth conditions are clearly separated, and category $\mathrm{C}$ (including the majority of catabolic enzymes) represents the component showing the most pronounced difference between both strains - to a lesser extent also category I for Dn. magnum (online suppl. Fig. S1a, b). For Dn. limicola, second degree variance is mainly caused by differences in categories $\mathrm{E}, \mathrm{J}$, and $\mathrm{S}$. The clear dominance of categories $\mathrm{S}$ and $\mathrm{NiC}$ in PC2 differences of Dn. magnum underscores the importance of proteins of unknown function (S) and with no assignment to any COG category $(\mathrm{NiC})$ for the physiology of this species. Despite the rather similar catabolic routes for fumarate and succinate, the proteomic response of both strains is apparently not only restricted to (small) catabolic adaptations (reflected by small distances in PC1), but also includes other cellular processes yielding separation in PC2. Interesting$\mathrm{ly}$, this second component difference appears to be comparable between both strains, since fumarate and succinate data points reveal rather congruent distance patterns, indicating a similar influence as, for example, the redox state of the substrate (i.e., energy yield possible). The clustering of butyrate and propionate in vicinity of aromatic substrates in case of Dn. magnum may in part be attributed to their toxic effects that, similar to the solvent properties of the aromatic compounds, lead to a pronounced stress response. The latter possibly involves rearrangement of the fatty acid and phospholipid composition, as previously observed with denitrifying Aromatoleum aromaticum $\mathrm{EbN}^{\mathrm{T}}$ [ [Trautwein et al., 2008; Zink and Rabus, 2010]. This hypothesis finds support by the here revealed importance of COG category I.
Schnaars/Wöhlbrand/Scheve/Hinrichs/ Reinhardt/Rabus 
When both organisms are included in this analysis, separation of growth conditions is preserved, but a clear affiliation according to the organisms is evident (Fig. 2b bottom), indicating a generally different proteomic response to (in part similar) growth conditions and, hence, an individual fashion of using the respective genomic potential.

\section{Catabolic Network}

Based on the complete genomes of Dn. limicola and Dn. magnum and the respective differential proteomic datasets, the catabolic networks as well as their substratedependent regulation were elucidated. These findings are summarized in consecutive Figures 3-5: Figure 3 illustrates the genetic blueprints of both strains underlying individual pathway modules, including the identification status of the encoded proteins. Figure 4 provides an integrated representation of the catabolic networks constructed for both studied strains. Figure 5 displays a heatmap of the substrate-specific protein profiles across the two catabolic networks, visualizing the various degrees of regulatory stringency. Underlying annotation data are compiled in online suppl. Table S2 and corresponding proteomic data for all substrate conditions tested with the two Desulfonema strains are presented in detail in online suppl. Table S3. Overall, the catabolic networks of $D n$. limicola and Dn. magnum are composed of 98 and 145 proteins, respectively, which are proteomically covered by 92.5 versus $89.7 \%$, and the coding genes of which have cumulative genomic shares of 1.6 versus $1.5 \%$ (Fig. 2 c).

\section{(i) Aromatic Compound Degradation}

The capacity to utilize aromatic compounds for growth, previously reported to be specific for Dn. magnum [Widdel et al., 1983], requires 48 genes ( $87.7 \%$ pro-

Fig. 2. Proteogenomic datasets for Dn. limicola and Dn. magnum. a Distribution of coding sequences and their proteomic coverage across the clusters of orthologous groups of proteins (COG). COG categories (in alphabetic order): A, RNA processing and modification; $\mathrm{B}$, chromatin structure and dynamics; $\mathrm{C}$, energy production and conservation; $\mathrm{D}$, cell cycle control, cell division, chromosome partitioning; E, amino acid transport and metabolism; F, nucleotide transport and metabolism; G, carbohydrate transport and metabolism; H, coenzyme transport and metabolism; I, lipid transport and metabolism; J, translation, ribosomal structure and biogenesis; K, transcription; L, replication, recombination, repair; $M$, cell wall/membrane/envelope biogenesis; $\mathrm{N}$, cell motility; $\mathrm{NiC}$, not in COG; O, posttranslational modification, protein turnover, chaperones; $\mathrm{P}$, inorganic ion transport and metabolism; $\mathrm{Q}$, secondary metabolites biosynthesis, transport and catabolism; R, general function prediction only; $\mathrm{S}$, function unknown; $\mathrm{T}$, signal teomic coverage) for the degradation of benzoate, phenylacetate, 3-phenylpropionate, $p$-cresol, and 4-hydroxybenzoate (Fig. 4). These genes are mostly clustered in operon-like structures (Fig. 3a) and completely absent from the genome of Dn. limicola. The uptake of phenylacetate supposedly occurs via a specifically formed TRAP transporter, similar to $\mathrm{Db}$. toluolica Tol2 [Wöhlbrand et al., 2013] and Dc. multivorans [Dörries et al., 2016a], while that of the other tested aromatic compounds remains unclear at present. The peripheral conversion of the tested aromatic compounds to the central intermediate benzoyl-CoA (Fig. 4) follows the reaction sequences previously resolved by proteogenomics for $\mathrm{Db}$. toluolica Tol2 [Wöhlbrand et al., 2013], Dc. multivorans [Dörries et al., 2016a], and Ar. aromaticum $\mathrm{EbN}^{\mathrm{T}}$ [Rabus et al., 2014]. For example, $p$-cresol degradation is initiated via addition to fumarate forming 4-hydroxybenzylsuccinate, which is followed by modified $\beta$-oxidation yielding benzoyl-CoA and succinyl-CoA. Conversion of phenylacetate to benzoyl-CoA involves $\alpha$-oxidation as originally discovered in denitrifying Thauera aromatica $\mathrm{K}_{172}{ }^{\mathrm{T}}$ [Schneider and Fuchs, 1998]. The degradation of the lignin-monomer phenylpropionate to benzoyl-CoA occurs via $\beta$-oxidation of the acyl side chain as previously described for Ar. aromaticum $\mathrm{EbN}^{\mathrm{T}}$ [Trautwein et al., 2012]. For reductive dearomatization of benzoyl-CoA via the ATP-independent benzoyl-CoA reductases (class II $\mathrm{BCR}$ ), subsequent ring-cleavage and $\beta$-oxidation to acetyl-CoA moieties, the central benzoyl-CoA pathway of strict anaerobes is employed [Boll et al., 2016]. Notably, besides the catabolic proteins, the operons related to degradation of $p$-cresol, 3-phenylpropionate, and benzoate encode electron transfer flavoproteins (ETF) as well as a corresponding ETF:quinone oxidoreductases (Eqo) that are substrate-specifically formed (Fig. 3a, 5; online suppl.

transduction mechanisms; $\mathrm{U}$, intracellular trafficking, secretion, vesicular transport; $\mathrm{V}$, defense mechanisms; $\mathrm{W}$, extracellular structures; X, mobilome: prophages, transposons; $Y$, nuclear structure; Z, cytoskeleton. Mapping to Dn. limcola versus Dn. magnum and protein prediction versus identification is indicated in the insert. Underlying data are compiled in online suppl. Table S1. b PCA plots considering the portion of proteins detected of the genomic potential per COG category for Dn. limicola (top), Dn. magnum (center), and both strains combined (bottom). Abbreviations (in alphabetic order): But, butyrate; $\mathrm{Bz}$, benzoate; $p$-Cre, $p$ cresol; Lac, lactate; FA-Mix, fatty acid mixture; Fum, fumarate; Mal, malate; 4OHBz, 4-hydroxybenzoate; Phac, phenylacetate; 3-Ppp, 3-phenylpropionate; Prop, propionate; PropOH, propanol; Suc, succinate. c Proteomic coverage and genomic share across major modules of the catabolic network (see Fig. 3) comparing the two Desulfonema strains.

(For figure see next page.) 


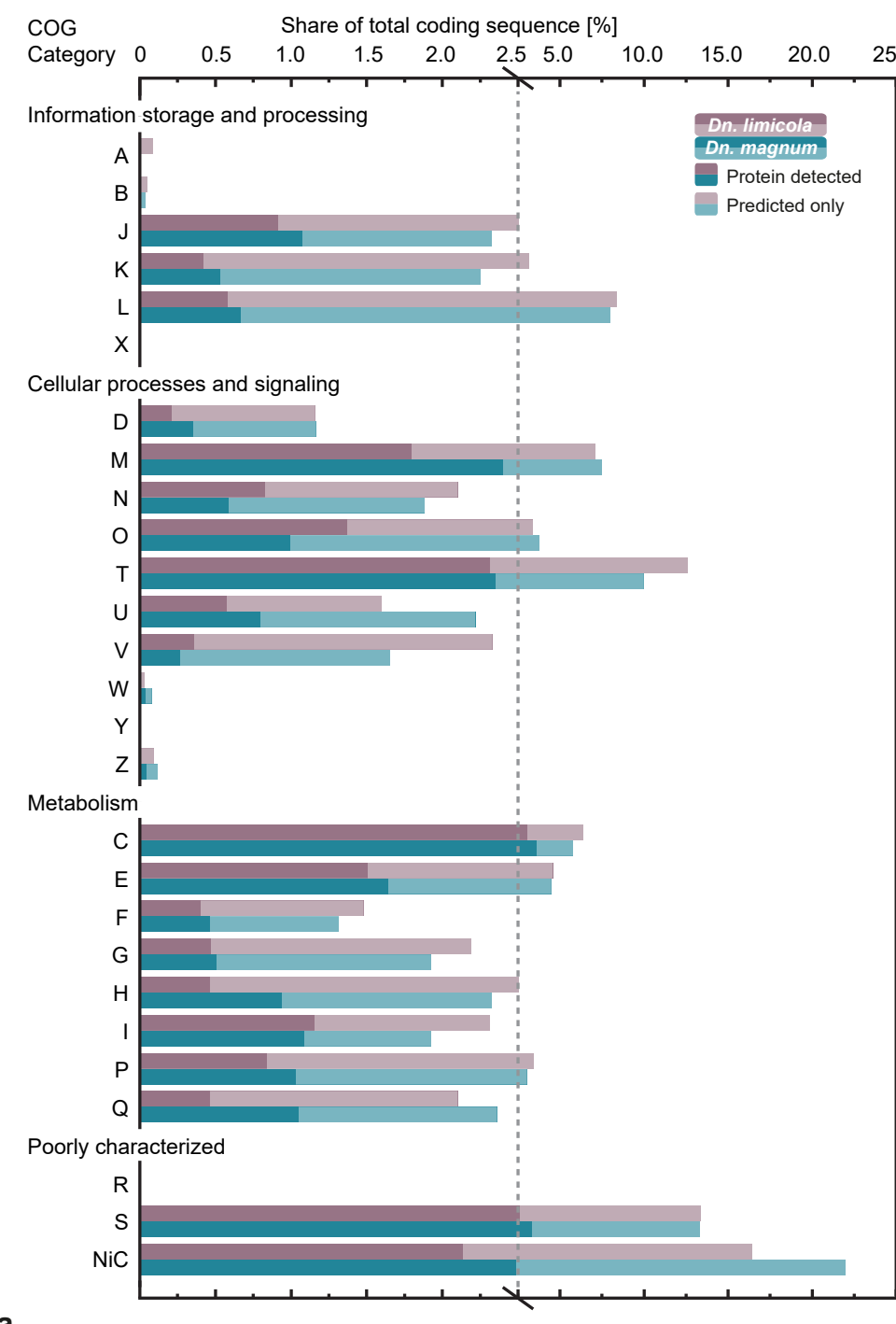

a

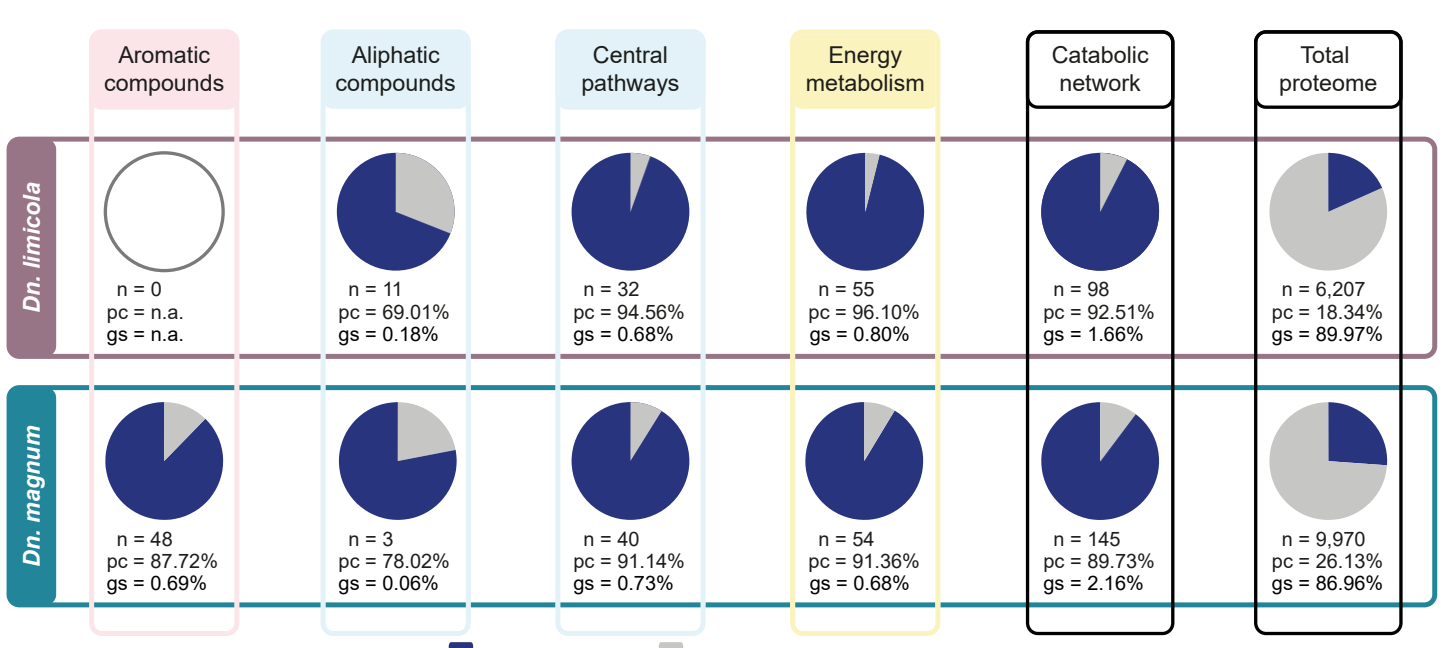

C

Protein detected Predicted only n: number of genes pc: proteomic coverage gs: genomic share 


\section{Aromatic compound degradation - Dn. magnum only}

p-Cresol (3)

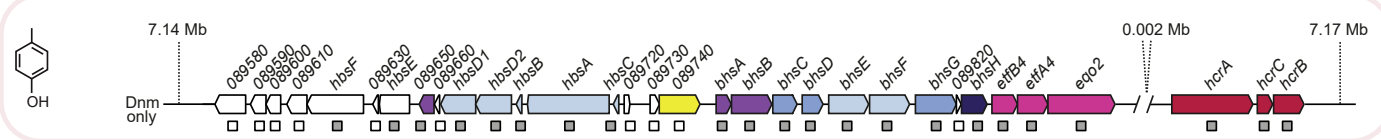

3-Phenylpropionate (4)

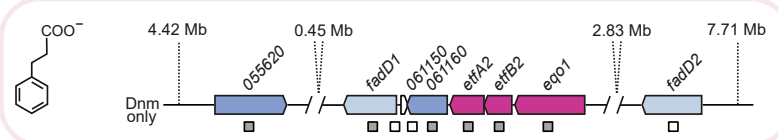

Phenylacetate (5)

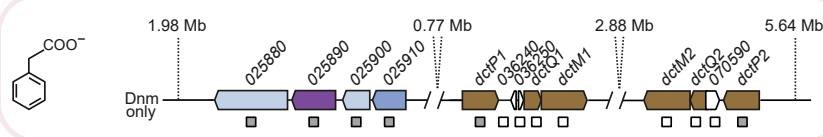

Benzoate (2) and Benzoyl-CoA pathway

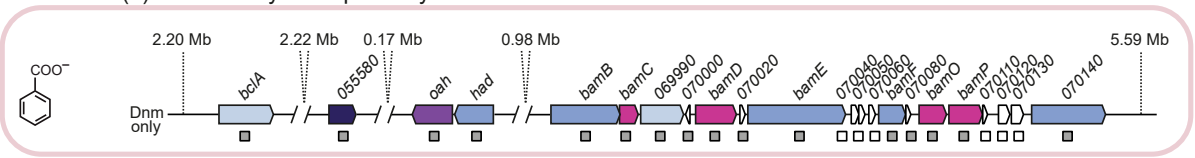

\section{Aliphatic compound degradation}

Lactate (11)

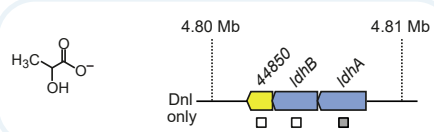

Propanol (6)

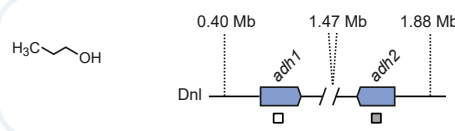

Propionate (7)

$\mathrm{H}_{3} \mathrm{C} \mathrm{N}_{\mathrm{O}^{-}}$

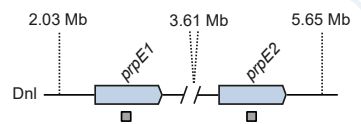

Methylmalonyl-CoA pathway
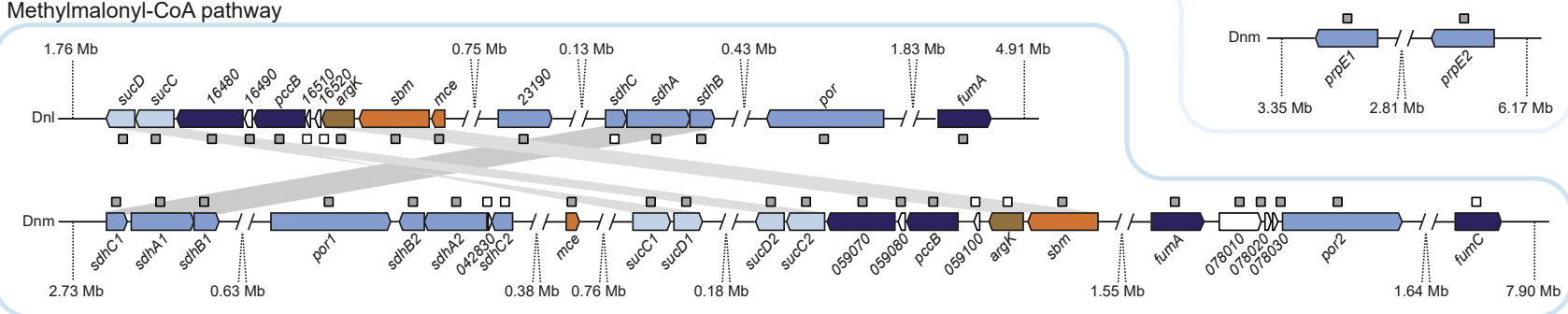

\section{$\beta$-Oxidation}
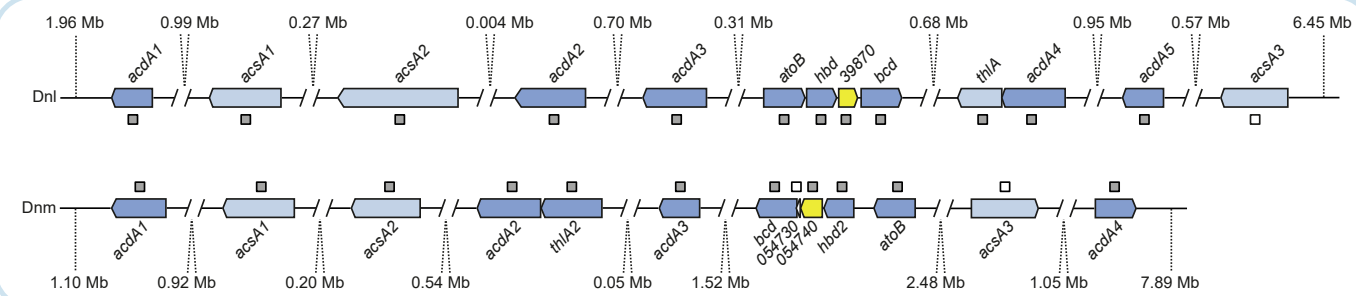

Wood-Ljungdahl pathway

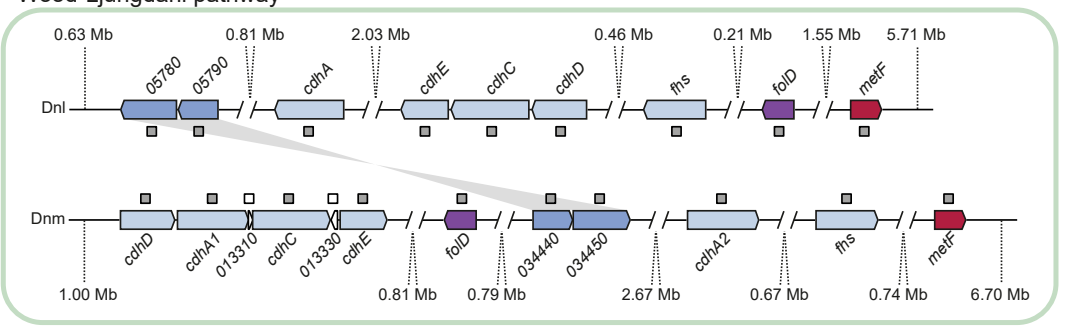

Autotrophic growth - Dn. limicola only

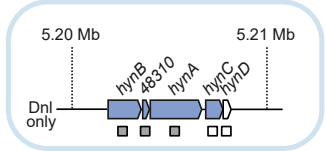

b

3

(Figure continued on next page.) 
Energy metabolism

Dissimilatory sulfate reduction

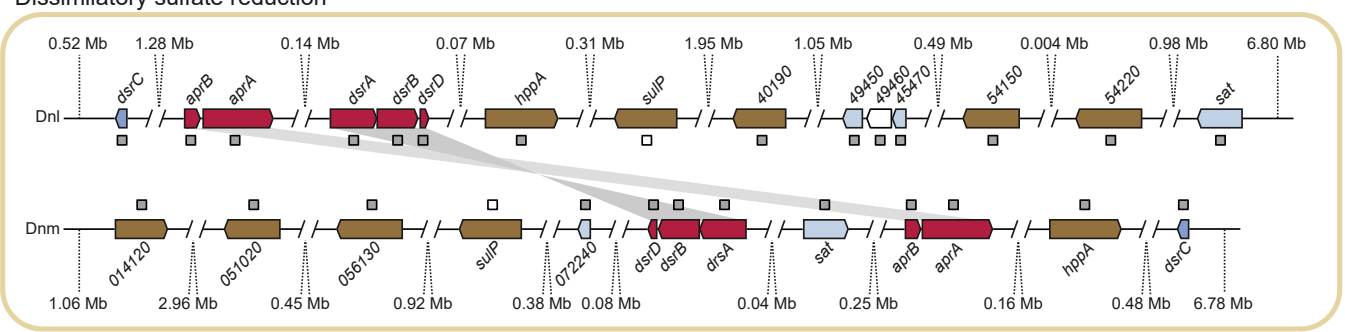

Redox complexes

(i) Quinone-interacting membranebound oxidoreductase, QmoABC

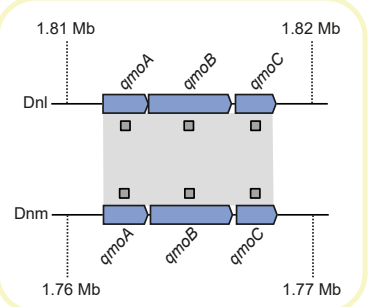

(iv) Menaquinone reductase, $\operatorname{QrcABCD}$

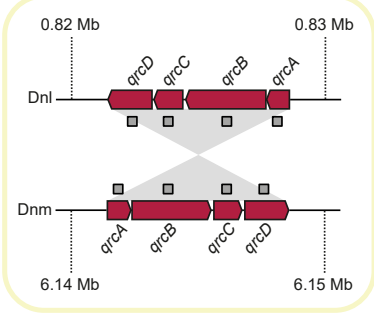

(ii) DsrMKJOP complex

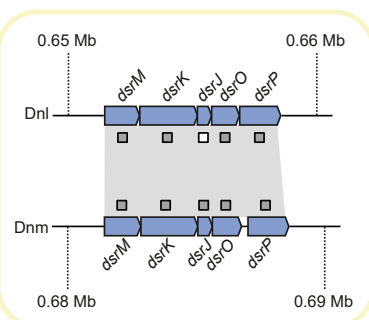

(iii) Tetrahaem cytochrome complex, TmcABCD

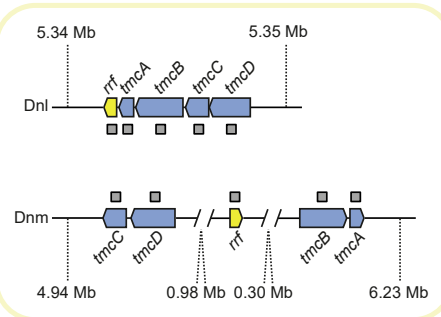

(v) Ferredoxin:NAD+-oxidoreductase, RnfABCDEG
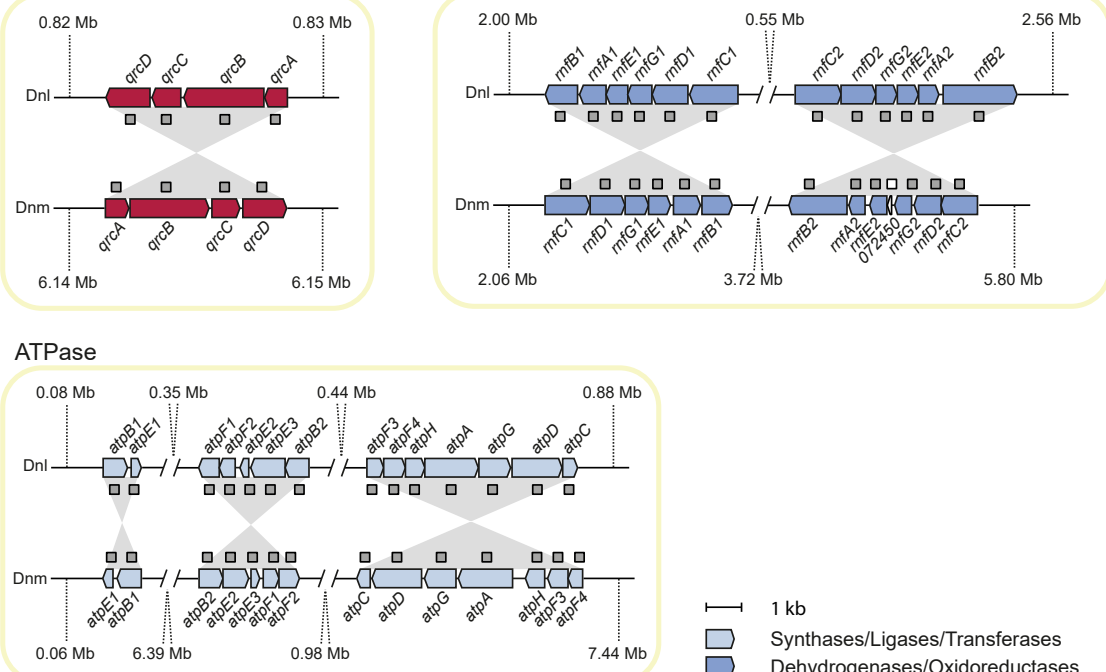

C

Fig. 3. Gene organisation in Dn. limicola (Dnl) and Dn. magnum (Dnm) with respect to anaerobic degradation of aromatic (a) and aliphatic (b) compounds (numbering as in Fig. 1) and to energy metabolism (c). Color coding of genes according to functional groups is indicated in the insert. Gray and white boxes below the genes denote gene products that have been identified or predicted only, respectively. Predicted functions of gene products and underlying proteomic data are compiled in online suppl. Tables S2 and S3. Homologous gene clusters are indicated by gray wedges. 


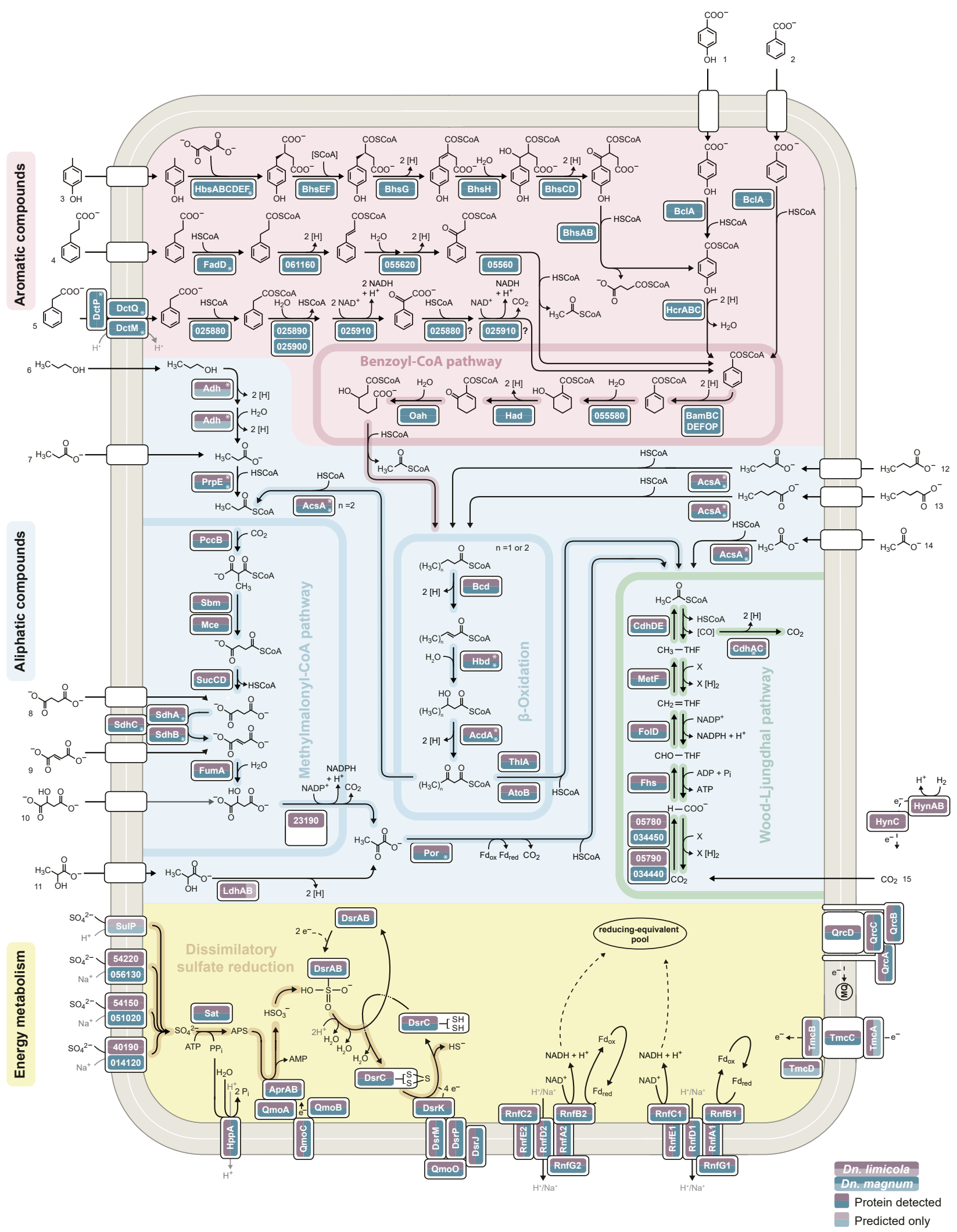

(For legend see next page.) 
Table S3). Organization of all pathway-required proteins, including transfer of pathway-derived electrons via specific ETF:Eqo systems to the menaquinone-pool, was initially described for $\mathrm{D} b$. toluolica Tol2 [Wöhlbrand et al., 2013], subsequently also observed in case of Dt. autotrophicum HRM2 [Dörries et al., 2016b] as well as Dc. multivorans [Dörries et al., 2016a], and biochemically characterized with $\mathrm{Db}$. toluolica Tol2 and other (facultative) anaerobes [Vogt et al., 2019]. Hence, such a modular genomic structure may represent another functional building block for the success of energy-limited Desulfobacteraceae members in the environment.

The subproteomes of these catabolic modules for aromatic compounds are formed at varying degrees of specificity in Dn. magnum (Fig. 5). Firstly, proteins constituting peripheral reaction sequences (yielding benzoyl-CoA) display profiles of high substrate specificity, which is most pronounced for 3-phenylpropionate and $p$-cresol. Secondly, key enzymes of the central benzoyl-CoA pathway, in particular class II BCR, are formed with all tested aromatic growth substrates, but not or only at markedly lower abundance with aliphatic compounds. Thirdly, downstream components of the benzoyl-CoA pathway concerned with $\beta$-oxidation are also observed in cells adapted to growth with aliphatic substrates. Taken together, these subproteome profiles are in good agreement with observations from previous studies on $\mathrm{Db}$. toluolica Tol2 [Wöhlbrand et al., 2013] and Dc. multivorans [Dörries et al., 2016a].

\section{(ii) Aliphatic Compound Degradation}

The catabolic module for aliphatic substrates comprises the least number of compound-specific protein constituents. The most apparent difference in the utilization of aliphatic compounds between Dn. limicola and Dn. magnum is the incapacity of the latter to grow with lactate, an archetypical substrate for SRB. Accordingly, the genome of Dn. magnum lacks the genes for a lactate dehydrogenase, which by contrast is specifically formed in Dn. limicola.

Fig. 4. Composite catabolic network of Dn. limicola and Dn. magnum. Assignment of protein constituents to the two Desulfonema strains and the state of identification is indicated in the insert. $\mathrm{Pu}$ tative electron flow is indicated by dashed lines. Proteins marked with stars $\left(^{*}\right)$ are present as paralogs in the respective organism. Compound numbering and names are as detailed in the legend to Fig. 1. Predicted functions of gene products and underlying proteomic data are compiled in online suppl. Tables S2 and S3. (iii) Central Degradation Pathways

Classical $\beta$-oxidation of fatty acids splitting off acetylCoA moieties, the methylmalonyl-CoA pathway converting propionyl-CoA into acetyl-CoA, and the WoodLjungdahl pathway terminally oxidizing acetyl-CoA to $\mathrm{CO}_{2}$ constitute the central degradation pathways shared by $\mathrm{Dn}$. limicola (32 genes, $94.6 \%$ proteomic coverage) and Dn. magnum (40 genes, $91.1 \%$ proteomic coverage). In contrast to aromatic compound catabolism, the genes for these central pathways are not organized in pathwayspecific modules, but rather randomly scattered across the respective genome, which is reminiscent of the other genome-sequenced Desulfobacteraceae members. Only enzymes of the methylmalonyl-CoA pathway have partly clustered genes (e.g., succinate CoA-ligase, malic enzyme, and propionyl-CoA carboxylase) in both Desulfonema strains (Fig. 3b). Interestingly, the gene order in the cluster for the methylmalonyl-CoA pathway is different, which is also the case for genes of the Wood-Ljungdahl pathway. The identified protein constituents of all 3 central degradation pathways are essentially constitutively formed across all tested substrate conditions (Fig. 5).

\section{(iv) Chemolithoautotrophy}

The ability of Dn. limicola to grow chemolithoautotrophically with $\mathrm{H}_{2}$ and $\mathrm{CO}_{2}$ as sole sources of energy and carbon, respectively, is based on the presence of hydrogenase (HynA-D) and the reductive Wood-Ljungdahl pathway [Schauder et al., 1989]. Noteworthy, the Hyn hydrogenase is formed under all substrate conditions tested for Dn. limicola, but no other types of hydrogenase as previously observed in a proteomic study with Dt. autotrophicum HRM2 [Dörries et al., 2016b]. Absence of genes encoding hydrogenase is apparently causative for the inability of Dn. magnum to grow with $\mathrm{H}_{2} / \mathrm{CO}_{2}$.

\section{(v) Energy Metabolism and Redox Complexes}

Both Desulfonema strains apparently apply sodiumdriven symporters to import sulfate for subsequent cytoplasmic sulfate reduction. The latter proceeds according to the conserved reaction sequence for dissimilatory sulfate reduction via Sat, $\mathrm{AprAB}$, and DsrABC, involving membrane protein complexes for pyrophosphate hydrolysis (HppA) and delivery of electrons for APS and sulfite reduction (QmoABC and DsrJKMP). Furthermore, both Desulfonema strains possess additional membrane-located, electron-transferring complexes (Rnf1, Rnf2, Tmc, and Qrc) involved in other relevant redox processes (e.g., Rnf in sodium-linked bioenergetics), which were to the 
Fig. 5. Heat-map representation of substrate-specific proteome profiles of $D n$. limicola and Dn. magnum. Growth substrates analyzed in both organisms are highlighted in bold. Compound numbering is as in Fig. 1. Scale of meta scores underlying protein identification is shown at the bottom. Absence of paralogue is indicated in gray. Proteins are sorted as indicated by color-coded grouping (left). Abbreviations are as detailed in the legend to Fig. 2.

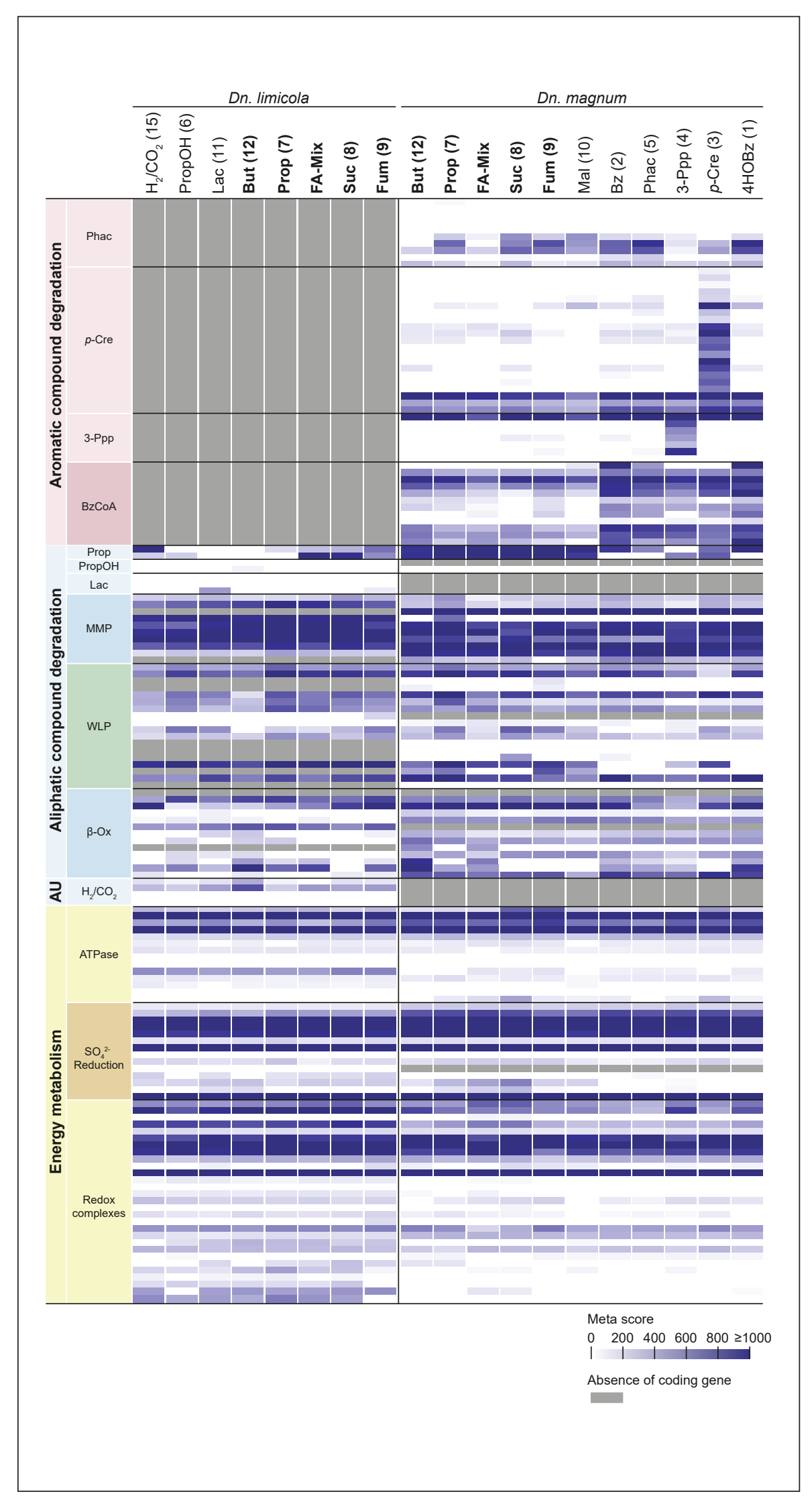

Microb Physiol 2021;31:36-55 DOI: $10.1159 / 000513383$ 
Table 2. Lifestyle-relevant genomic repertoire ${ }^{a}$

\begin{tabular}{|c|c|c|c|c|}
\hline \multirow[t]{2}{*}{ Predicted function } & \multicolumn{2}{|l|}{ Gene(s) } & \multicolumn{2}{|c|}{ Status ${ }^{b}$} \\
\hline & Dn. limicola (Dnl) & Dn. magnum (Dnm) & Dnl & Dnm \\
\hline
\end{tabular}

\section{Cytoskeleton}

Cell division protein (tubulin-like)

Min-system

Cell division protein (actin-like)

Bactofilin domain-containing protein

Putative polymer-forming cytoskeletal bactofilin

Cell division

Cell shape-determining protein (actin-like)

Rod shape-determining protein $\mathrm{C}$

\section{Twitching motility}

Prepilin-type cleavage/methylation domain-containing protein (PilA-like) ${ }^{c}$

Type IV prepilin-like proteins leader peptide-processing enzyme

General secretion pathway protein E (PilB-like) ${ }^{\mathrm{c}}$

Twitching mobility protein

Type IV fimbrial assembly protein

Type IV pilus biogenesis and competence protein

Adventurous gliding (M. xanthus)

Mutual gliding-motility protein (intracellular switch)

\section{Exposure to molecular oxygen}

Superoxide dismutase

Catalase

Desulfoferrodoxin

Rubrerythrin

Rubredoxin oxidoreductase

Thiol peroxidase

Thioredoxin

Cytochrome $b d$ ubiquinol oxidase, $\alpha$-subunit

Cytochrome $b d$ ubiquinol oxidase, $\beta$-subunit

\section{Hyperosmotic stress}

Glycine betaine/proline betaine transport system

Substrate-binding protein

Permease protein

ATP-binding protein

Substrate-binding protein

Permease protein

ATP-binding protein

Substrate-binding protein

Permease protein

Transporter, BCCT family ${ }^{\mathrm{d}}$
Dnl_44430 (ftsZ)

Dnl_46180 (minE)

Dnl_46190 (minD)

Dnl_46200 (minC)

Dnl_44440 (ftsA)

Dnl 28030

Dnl_08050

Dnl 08000 (mreB1)

Dnl_16830 (mreB2)

Dnl_44740(mreB3)

Dnl_08010(mreC)

Dnl_15920

Dnl_38440 (pilD)

Dnl_24430 (gspE2)

Dnl_07850 (gspE1)

Dnl 13080 (pilT1)

Dnl_13090 (pilT2)

Dnl_28420 (pilC)

Dnl_15850 (pilQ1)

Dnl_60590(pilQ2)

Dnl_24490 (mglA1)

Dnl_35750 (mglA2)

Dnl_13760 (sodD)

Dnl_39890 (katA)

Dnl_13990 $(d f x)$

Dnl_04120(rbr)

Dnl_15040 (rub1)

Dnl_26780 (rub2)

Dnl_21750 (tpx)

Dnl_04600 (trxA1)

Dnl_12230 (trxA2)

Dnl_19500(trxA3)

Dnl_41830 (trxA4)

Dnl_13950 (cydA)

Dnl_13940 (cydB)

Dnl_32390

Dnl_32400

Dnl_32410

Dnl_48560

Dnl_57710
Dnm_000670 (ftsZ)

Dnm_082240 (minE)

Dnm_082230 (minD)

Dnm_082220 (minC)

Dnm_000660 (ftsA)

Dnm 078840

Dnm_093090

Dnm 093150 (mreB3)

Dnm_010210 (mreB2)

Dnm_010190 (mreB1)

Dnm_087180 (mreB-like)

Dnm_093140 (mreC)

Dnm_080970

Dnm_006120 (pilD)

Dnm_052530 (gspE)

Dnm_086960 (pilT2)

Dnm_086920 (pilT1)

Dnm_083070 (pilC)

Dnm_028790 (pilQ)

Dnm_027490 (mglA1)

Dnm_059280 (mglA2)

Dnm_072600

Dnm_031080 (katA)

Dnm_085620 (dfx)

Dnm_083040 (rbr1)

Dnm_085640 (rbr2)

Dnm_072290 (rub1)

Dnm_087830 (rub2)

Dnm_016000 (tpx)

Dnm_005330 (trxA2)

Dnm_062440 (trxA1)

Dnm_085570 (cydA)

Dnm_085560 (cydB)

Dnm_029760

Dnm_029780

Dnm_029850

Dnm_019300

Dnm_019320

Dnm_019330

Dnm_029830

Dnm 029840

$\square$
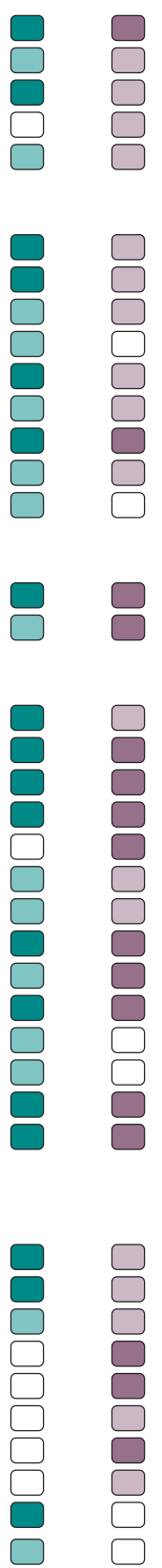

48

Microb Physiol 2021;31:36-55

DOI: $10.1159 / 000513383$
Schnaars/Wöhlbrand/Scheve/Hinrichs/ Reinhardt/Rabus 
Table 2 (continued)

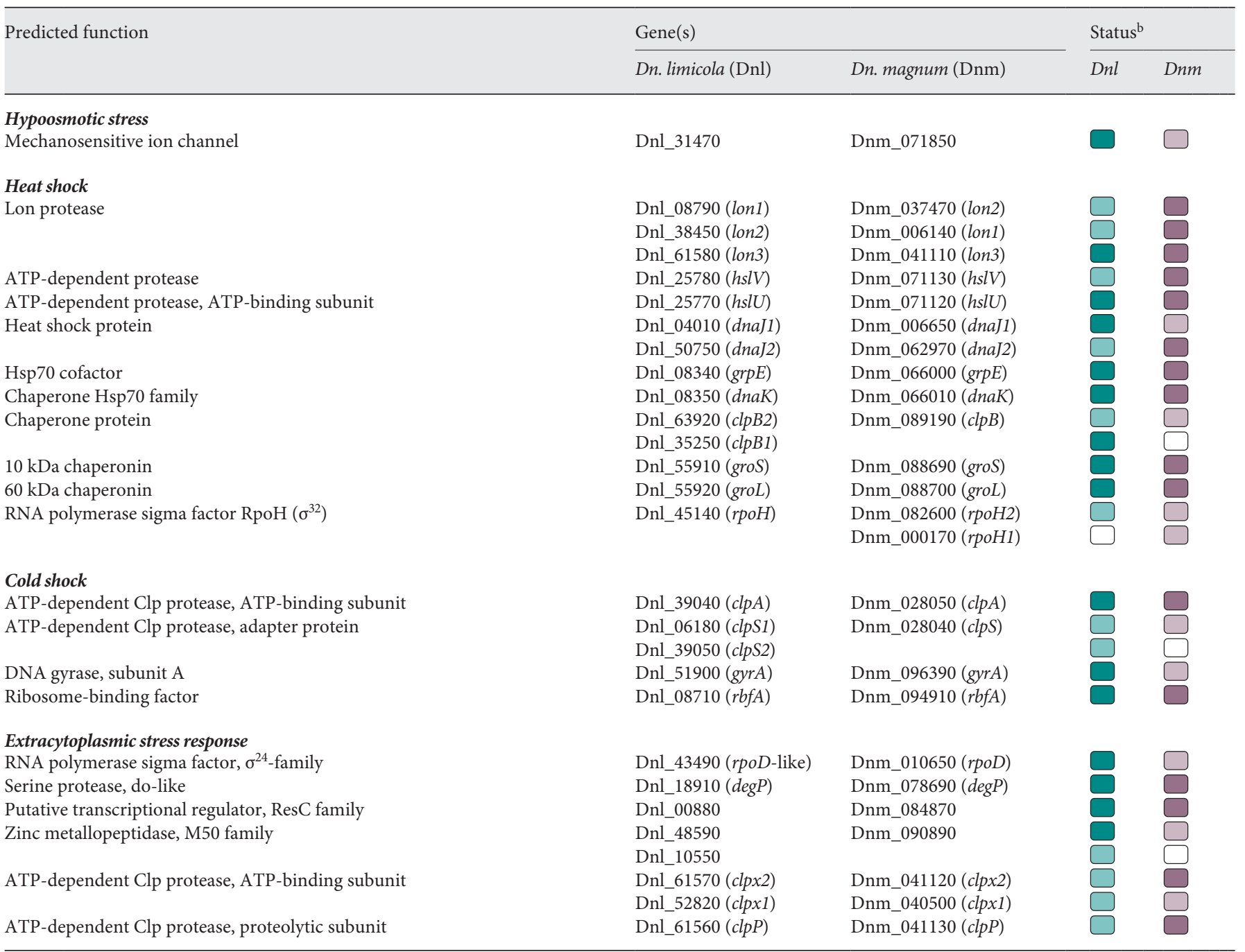

${ }^{a}$ Details of genes and proteomic identification are provided in online supplementary Table S $3 .{ }^{\mathrm{b}}$ Color coding: white, genes absent; light versus dark teal (Dnl)/mauve (Dnm) indicate gene predicted only versus gene product identified. ${ }^{c}$ Assignment to PilA and PilC ambiguous. ${ }^{d}$ BCCT, betaine-choline-carnitine transport.

largest part identified in the membrane protein-enriched fractions. In general, the protein constituents of energy metabolism and redox complexes were constitutively formed in both Desulfonema strains ( 50 genes, $>90 \%$ proteomic coverage).

\section{Lifestyle-Relevant Properties}

Typifying properties of Desulfonema spp. are their filamentous morphology (accompanied by gliding movement on surfaces) and their occurrence in environments characterized by physicochemical gradients (e.g., cyanobacterial microbial mats), suggesting the need to sense and respond to fluctuating environmental conditions.
Genes that can be assigned to these lifestyle properties are compiled in Table 2 with underlying genomic predictions as well as respective proteomic profiles detailed in online supplementary Tables S4 and S5.

(i) Cell Division, Cytoskeleton, and Motility

A variety of filament- and pattern-forming proteins are known in prokaryotes that are involved in cell division, determining cell shape and other cell biology functions [e.g., Haeusser and Margolin, 2016; Ramm et al., 2019; Wagstaff and Löwe, 2018]. Filamentous FtsZ (tubulin-like) forms the Z-ring as central part of the divisome and is assisted by FtsA (actin-like). Their spatiotemporal 
orientation at the division plain is controlled by the MinCDE system, preventing the Z-ring from assembling at the cell poles. Both Desulfonema strains possess the respective genes, and the majority of encoded proteins was detected in Dn. limicola, but only FtsZ in Dn. magnum (online suppl. Table S5). Furthermore, the genomes of both Desulfonema strains contain genes (no product detected) coding for bactofilin-like proteins, which can play various structural and functional roles in the cytoskeleton of bacteria [Kühn et al., 2010].

Formation of the elongated shape of bacterial cells essentially requires the MreB protein (actin-like) that organizes the elongasome, a multienzyme complex for cell wall synthesis. While both Desulfonema genomes encode several paralogous MreBs, only one is constitutively formed in each strain: MreB1 (Dn. limicola) and MreB3 (Dn. magnum), which share $89.1 \%$ sequence identity.

Desulfonema spp. were early on reported to migrate on surfaces by gliding movement [Widdel et al., 1983], raising the question about the underlying mechanism of motility. Therefore, the genomes of Dn. limicola and Dn. magnum were primarily searched for genes required for gliding movement (widespread type-IV pili as well as more special systems from Flavobacterium, Myxococcus xanthus, and Mycoplasma), but also for swimming by flagella as previously reviewed by Jarrell and McBride [2008]. Both investigated Desulfonema strains possess genes for twitching motility by means of type-IV pili ( $p$ il genes) and for adventurous gliding motility ( $m g l A$ genes) known from $M$. xanthus. While most protein constituents of these two systems were detected in Dn. limicola, this was only the case for PilC in Dn. magnum. By contrast, neither homologs of classical flagella genes ( $f l g, f l h$, $f l i, f l k$, or $m o t)$, genes for lateral movement by adhesins $(s p r B, g l d)$ located on the cell surface, nor genes for $M y$ coplasma-type gliding ( $p 42, \mathrm{gli})$ could be found in either of the two studied genomes. Noteworthy, a large portion of the proteins assigned to cell division, cytoskeleton, and motility was identified in Dn. limicola by the current proteomic analysis, while this was the case for only few with Dn. magnum.

Notably, some proteins of unknown function were related to a function in the cell envelope by the eggNOG database (assigned to the COG category M) and detected under all or a large number of studied growth conditions (online suppl. Table S5). For example, Dnl_52570 and Dnm_074620 were abundantly present under all tested conditions and also share $39.1 \%$ sequence identity, suggesting a similar function in both organisms. Also the second most abundant of these proteins of unknown func- tion assigned to COG M in Dn. magnum (Dnm_000300) shares similar identity with a Dn. limicola homolog (Dnl_50070), further supporting the hypothesis that proteins of so far unknown function could be involved in the characteristic morphology of Desulfonema spp. Overall, the differences in the protein complement related to morphology and movement formed by the two species fit well to the microscopic observation originally reported by Widdel et al. [1983].

\section{(ii) Adaptation to Redox Gradient Systems}

As noted before, Desulfonema phylotypes have repeatedly been detected in cyanobacterial mats, which are characterized by diurnal changes between oxygen saturation during the light period and high sulfide concentrations due to high sulfate reduction rates [Revsbech et al., 1983; Fründ and Cohen, 1992]. This suggests Desulfonema spp. to be capable of dealing with toxic oxygen species, despite SRB being generally considered as strict anaerobes. In fact, Desulfovibrio spp. have been reported to adopt several strategies for protecting against oxygen stress, including flocculation [Sigalevich et al., 2000], rubrerythrin, and rubredoxin oxidoreductase in addition to classical superoxide dismutase and catalase [Lumppio et al., 2001], as well as oxygen respiration [Cypionka, 2000]. Both studied Desulfonema strains have at their disposal the full spectrum of proteins for protection against oxygen stress, comprising superoxide dismutases, catalase, desulfoferrodoxin, rubrerythrin, and thiol peroxidase, all of which could be identified. The two strains possess genes for rubredoxin oxidoreductase, albeit the products of which were not identified under the tested substrate conditions. Furthermore, both Desulfonema strains form a cyctochrome $b d$ ubiquinol oxidase, which one may speculate to participate in oxygen respiration as a means to reduce the $\mathrm{pO}_{2}$ rather than to gain energy [Cypionka, 2000]. By contrast, both strains lack the genes for dissimilatory reduction of nitrate (to $\mathrm{N}_{2}$ ). Taken together, Dn. limicola and Dn. magnum are well equipped to cope with periods of exposure to molecular oxygen in their natural environment, in particular occurring in microbial mats that perform oxygenic photosynthesis.

\section{(iii) Adaptation to Stress Conditions}

Demanding environmental conditions, such as recurring osmotic and temperature stress, are inherent to habitats like microbial mats and intertidal sediments. Desiccation increases osmolarity leading to collapse of the cell turgor, which various bacteria countervail by accumulating organic osmolytes (compatible solutes) preferentially
Schnaars/Wöhlbrand/Scheve/Hinrichs/ Reinhardt/Rabus 
via active uptake [Kempf and Bremen, 1998; Krämer, 2010; Wood, 2011]. The genomes of both Desulfonema strains harbor genes encoding various $\mathrm{ABC}$ transporters for the compatible solutes glycine betaine and proline betaine [e.g., Teichman et al., 2018], with several subunits being detected in the current proteomic dataset. Dn. limicola in addition possesses genes for two members of the ion-driven transporters of the BCCT-family (betaine, choline, carnitine) [Ziegler et al., 2010], one of which was detected. By contrast, sudden decrease in external solute concentration (e.g., by rain at low tide) causes rapid water influx into the cell and thereby increase in cell turgor (hypoosmotic stress), which bacteria overcome by using mechanosensitive channels [Morbach and Krämer, 2002]. Such a channel is encoded by a single gene in each of the two studied genomes and the respective product was detected in case of $D n$. limicola. Taken together, $D n$. limicola and Dn. magnum possess the transporter equipment to deal with hyper- as well as hypoosmotic stress.

The natural habitats of Desulfonema spp., e.g., microbial mats residing in hot climates [Minz et al., 1999], can furthermore be expected to challenge microorganisms due to thermal stress. At increasing temperatures, bacteria conduct heat shock response to maintain proteinfolding homeostasis by rapidly forming various proteases and chaperones, transcriptionally controlled by the sigma factor $\sigma^{32}(\mathrm{RpoH})$ [Guisbert et al., 2008; Spiess et al., 1999]. Accordingly, the genomes of both studied Desulfonema strains encode several proteases (3 paralogs of Lon, HslUV), heat shock proteins (2 paralogs of DnaJ, DnaK), chaperons (ClpP, GroSL), and the specific sigma factor itself (RpoH). Notably, for Dn. magnum all 3 predicted Lon proteases were detected, while only 1 was detected in case of Dn. limicola. Lon proteases contribute to cellular homeostasis by decomposing abnormal and certain regulatory proteins [Mahmoud and Chien, 2018]. In general, bacterial response to decreasing temperature includes the formation of a variety of specific (cold shock) proteins to maintain viability of cells at low temperatures. Out of the known cold shock-induced proteins from $E$. coli [Phadtare and Inouye, 2008], the genomic repertoires of Dn. limicola and Dn. magnum include the ribosomebinding factor RbfA, ATP-dependent protease ClpAS and gyrase GyrA. Taken together, both Desulfonema strains are well equipped to maintain cellular function upon up- or downshift of ambient temperature.

Occurrence of Desulfonema spp. in the sheaths of Thioploca spp. [Teske et al., 2009], as well as their gliding movement [Widdel et al., 1983], can be expected to exert physical straining on their cell envelope, potentially leading to mis- folded outer membrane proteins. This could be countervailed by extracytoplasmic (or envelope) stress response (ESR), which has been well studied in model organisms, such as E. coli, in particular the response mediated by $\sigma^{\mathrm{E}}$ $\left(\sigma^{24}, \mathrm{RpoE}\right)$ [Bury-Mone et al., 2009; Rowley et al., 2006]. In E. coli, the $\sigma^{\mathrm{E}}$-regulon comprises a broad range of genes belonging to different functional categories, such as $\sigma$-factors, primary metabolism, proteases, or membrane lipid metabolism (see Table 1 in [Rowley et al., 2006]). Potential members of a $\sigma^{\mathrm{E}}$-regulon are also predicted and formed in both studied Desulfonema strains (online suppl. Tables S6 and S7), as well as $\sigma^{\mathrm{E}}$ itself and the associated ClpPX complex transforming $\sigma^{\mathrm{E}}$ into its active transcription-controlling form. Moreover, the periplasmic DegP protein, which controls protein stability and turnover in the periplasm and the expression of which is under control of $\sigma^{\mathrm{E}}$ [Spiess et al., 1999], is formed by both Desulfonema strains. However, the upfront part for the regulation of the $\sigma^{\mathrm{E}}$ activity, i.e., the membrane-localized proteins ResA ( $\sigma^{\mathrm{E}}$-binding) and DegS (ResA-cleaving in the presence of misfolded OMPs), are apparently not encoded in the genome of the two studied Desulfonema strains. Thus, the ESR in Desulfonema spp. has some unclear facets, possibly differing in parts from the mechanism elucidated with E. coli.

\section{Conclusions}

The present proteogenomic study suggests the success of the two filamentous sulfate reducers Dn. limicola and Dn. magnum in their highly dynamic habitats (e.g., tidal marine sediments or cyanobacterial mats) to rely on the large genomic arsenal of stress response mechanisms as well as the metabolic flexibility considering the broad range of utilizable substrates. Furthermore, this genomic potential is apparently employed when appropriate (e.g., substrate availability), mediated by a substantial network of regulatory proteins. It seems plausible that the demanding habitat conditions may have promoted lateral acquisition of functionally advantageous genes from other habitat members and, hence, yielded the increased genome size - a hypothesis supported by the large repertoire of mobile genetic elements. While these properties are generally also characteristic for other Desulfobacteraceae members, the genomes (and proteomes) of the two studied Desulfonema strains harbor a number of conspicuous features that may be related to their unique characteristics as filamentous, gliding SRBs and provide a solid basis for future investigations into their cell biology. 


\section{Materials and Methods}

Strains, Media, and General Cultivation Conditions

Desulfonema limicola $5 \mathrm{ac} 10^{\mathrm{T}}$ (DSM 2076) and Desulfonema magnum 4be13 ${ }^{\mathrm{T}}$ (DSM 2077) were originally isolated by Widdel [1983] with acetate and benzoate, respectively. For the present study, living cultures of both strains were obtained from Fritz Widdel (Bremen, Germany) and subcultured in our laboratory since then. Both strains were cultivated under sulfate-reducing conditions in a defined, sulfide-reduced, and bicarbonate-buffered mineral medium essentially as previously described by Widdel et al. [1983] with modification derived from Rabus et al. [1993]. The defined mineral medium for Dn. limicola was composed of $4 \mathrm{~g} / \mathrm{L} \mathrm{Na}_{2} \mathrm{SO}_{4}, 0.2 \mathrm{~g} / \mathrm{L} \mathrm{KH}_{2} \mathrm{PO}_{4}, 0.25$ $\mathrm{g} / \mathrm{L} \mathrm{NH}_{4} \mathrm{Cl}, 13.5 \mathrm{~g} / \mathrm{L} \mathrm{NaCl}, 2.2 \mathrm{~g} / \mathrm{L} \mathrm{MgCl}{ }_{2} \times 6 \mathrm{H}_{2} \mathrm{O}, 0.5 \mathrm{~g} / \mathrm{L} \mathrm{KCl}$, and $0.15 \mathrm{~g} / \mathrm{L} \mathrm{CaCl} \mathrm{Ca}_{2} \times 2 \mathrm{H}_{2} \mathrm{O}$, while that for Dn. magnum contained 4 $\mathrm{g} / \mathrm{L} \mathrm{Na}_{2} \mathrm{SO}_{4}, 0.15 \mathrm{~g} / \mathrm{L} \mathrm{KH}_{2} \mathrm{PO}_{4}, 0.2 \mathrm{~g} / \mathrm{L} \mathrm{NH}_{4} \mathrm{Cl}, 20 \mathrm{~g} / \mathrm{L} \mathrm{NaCl}, 5 \mathrm{~g} / \mathrm{L}$ $\mathrm{MgCl}_{2} \times 6 \mathrm{H}_{2} \mathrm{O}, 0.5 \mathrm{~g} / \mathrm{L} \mathrm{KCl}$, and $1.4 \mathrm{~g} / \mathrm{L} \mathrm{CaCl} \times 2 \mathrm{H}_{2} \mathrm{O}$. The media for both Desulfonema strains were further supplemented with $1 \mathrm{~mL} / \mathrm{L}$ each of trace element mixture, selenite/tungstate, vitamins $\mathrm{B}_{1}, \mathrm{~B}_{2}$, and $\mathrm{B}_{12}$, vitamin mixture, $1 \mathrm{M} \mathrm{Na}_{2} \mathrm{~S}$, and $30 \mathrm{~mL} / \mathrm{L} \mathrm{NaHCO}_{3}$. The medium for Dn. magnum was adjusted to $\mathrm{pH} 7$ and that for Dn. limicola to $\mathrm{pH}$ 7.6. To provide growth-supporting artificial surfaces, $5 \mathrm{~mL} / \mathrm{L}$ of $48 \mathrm{~g} / \mathrm{L} \mathrm{AlCl}_{3} \times 6 \mathrm{H}_{2} \mathrm{O}$ (Dn. limicola) and $95 \mathrm{~g} / \mathrm{L}$ $\mathrm{KAl}\left(\mathrm{SO}_{4}\right)_{2} \times 12 \mathrm{H}_{2} \mathrm{O}$ plus $1.6 \mathrm{~mL} / \mathrm{L}$ of $1 \mathrm{M} \mathrm{Na}_{2} \mathrm{CO}_{3}$ (Dn. magnum) were added to (precipitated in) the medium prior to inoculation as developed by Widdel et al. [1983]. For inoculation of 400-mL cultures, $5 \%(\mathrm{v} / \mathrm{v})$ preculture of $\mathrm{Dn}$. limicola and $2 \mathrm{~mL}$ floc suspension of Dn. magnum were used. Cultivation was conducted in $500-\mathrm{mL}$ flat glass bottles sealed with butyl rubber stoppers under an anoxic $\mathrm{N}_{2}: \mathrm{CO}_{2}(90: 10, \mathrm{v} / \mathrm{v})$ atmosphere at $28^{\circ} \mathrm{C}$, lying flat with careful turning once per day. Cultures of both Desulfonema strains were adapted to the respective substrate conditions over 5 passages, starting from cultures adapted to anaerobic growth with the fatty acids mixture. For chemolithoautotrophic growth, 400-mL cultures (in 1-L glass bottles) were provided with a $\mathrm{H}_{2}: \mathrm{CO}_{2}$ (80:20, $\mathrm{v} / \mathrm{v}$ ) atmosphere in the gas headspace and incubated at $100 \mathrm{rpm}$ on a platform shaker. Organic growth substrates were added from sterile stock solutions (final concentrations in $\mathrm{mm}$ indicated in parenthesis): lactate (10), propionate (10), butyrate (4), fatty acids mixture [acetate (10), succinate (1), propionate (1), and valerate $(0.5)$ ], succinate (10), fumarate (10), malate (10), $n$-propanol (10), phenylacetate (4), 3-phenylpropionate (5), p-cresol (3), and 4-hydroxybenzoate (4). Per substrate condition, at least 12 independent cultures were run to provide biological replicates for proteomic profiling. Due to the filamentous, surface-attached growth behavior of both Desulfonema strains, growth could not be monitored by measuring the optical density, but was rather determined indirectly on the basis of produced sulfide, by employing the methylene blue formation reaction as previously described [Aeckersberg et al., 1991]. Purity of the cultures was confirmed by microscopic examination (Axiostar; Zeiss AG, Göttingen, Germany). All chemicals were of analytical grade.

Harvesting of both Desulfonema strains was conducted at halfmaximal sulfide formation, included washing with buffer $(100 \mathrm{mM}$ Tris/ $\mathrm{HCl}, 5 \mathrm{mM} \mathrm{MgCl}_{2} \times 6 \mathrm{H}_{2} \mathrm{O}$, adjusted to $\mathrm{pH} 7$ ), considering the fragility of the filaments, and avoided cooling on ice in-between centrifugation steps. Dn. limicola cultures were slowly decanted into centrifuge cups and pelleted at $14,334 \mathrm{~g}\left(30 \mathrm{~min}, 12^{\circ} \mathrm{C}\right)$. Following washing and repeated centrifugation, cell suspensions were transferred to $2-\mathrm{mL}$ microreaction tubes and centrifuged $(20,817$ $g, 30 \mathrm{~min}, 12^{\circ} \mathrm{C}$ ). Then, the supernatant was carefully removed with a pipette yielding the final cell pellets. Dn. magnum cultures were placed in upright position for approximately $10-15 \mathrm{~min}$, allowing cell flocs to settle at the bottom of the glass bottles. Then, the supernatant was carefully decanted leaving $20-50 \mathrm{~mL}$ in the cultivation vessel. This remaining cell suspension was transferred to one $50-\mathrm{mL}$ reaction tube (with orifice wider than that of the glass bottles), which was subsequently filled up with washing buffer, carefully swung, and incubated in upright position for 10-15 min. This washing procedure was repeated 2 more times. Then, the supernatant was decanted as much as possible and the remaining cell suspension carefully distributed to $2-\mathrm{mL}$ microreaction tubes. After short centrifugation $\left(20,817 \mathrm{~g}, 2 \mathrm{~min}, 12^{\circ} \mathrm{C}\right)$, the supernatant was discarded, new cell suspension added, and centrifuged anew. This procedure was repeated until cells from a complete $400-\mathrm{mL}$ culture were concentrated. The final cell pellets of Dn. limicola and concentrated cells of Dn. magnum were immediately shock-frozen in liquid $\mathrm{N}_{2}$ and stored at $-80^{\circ} \mathrm{C}$ until further analyses.

\section{DNA Sequencing, Assembly, and Annotation}

Isolation of genomic DNA was carried out using the Genomic DNA kit (Qiagen, Hildesheim, Germany) according to the manufacturer's instructions. Recombinant plasmid and fosmid shotgun libraries were constructed, and plasmid libraries generated from sonified DNA as previously described [Rabus et al., 2005]. Additionally, a fosmid library was constructed ( $>40$-fold physical coverage) for data finishing and assembly confirmation (Epicentre Technologies, Madison, WI, USA). Templates for sequencing were obtained by insert amplification via PCR or by plasmid isolation. Sequencing was carried out using ABI3730XL capillary systems (ThermoFisher Scientific, Waltham, MA, USA). PHRAP (http://www.phrap.org/phredphrapconsed.html) and Consed [Gordon, 2003] were used to assess sequence quality and perform the assembly ( $>25$-fold coverage) with a quality of $<1$ error in 100,000 bases.

Structural rRNAs and tRNAs were determined using RNAmmer [Lagesen et al., 2007] and tRNAscan-SE [Lowe and Eddy, 1997]. CDS were predicted by the ORF-finding program Glimmer3 [Delcher et al., 1999] and manually revised and curated using Artemis (v.12.0) [Rutherford et al., 2000] and InterPro [Mitchell et al., 2019]. The generated ORF dataset was screened against nonredundant protein databases (SWISSPROT and TREMBL) [Bairoch and Apweiler, 2000] and the COG database [Galperin et al., 2015]. Genomic islands and islets $(<10 \mathrm{kbp})$ were predicted applying IslandViewer 3 [Dhillon et al., 2015]. The genome was screened for phage-like regions by PHASTER [Arndt et al., 2016], and CRISPR recognition tool [Bland et al., 2007] served in the detection of CRISPR sequences. The eggNOG database [Huerta-Cepas et al., 2019] was consulted for orthology prediction and functional categorization. Gene sequence comparisons between the two Desulfonema strains were examined via BioEdit Sequence Alignment Editor [Hall, 1999].

Analysis of genomic and proteomic data was conducted using Matlab version 2020a (MathWorks, Natick, MA, USA).

\section{Sequence Accession Numbers}

The genome sequences of Dn. limicola $5 \mathrm{ac} 10^{\mathrm{T}}$ and Dn. magnum 4 be $13^{\mathrm{T}}$ have been submitted to GenBank under the BioProjects PRJNA660367 and PRJNA660368, respectively, with accession numbers CP061799 and CP061800, respectively. 


\section{Proteomics}

(i) Analysis of the Membrane Protein-Enriched Fraction

For analyses of the membrane protein-enriched fraction, two biological replicate samples were prepared per growth condition and bacterial strain essentially as described [Koßmehl et al., 2013]. In brief, cell pellets were resuspended and disrupted by means of a FastPrep-24 5G bead beater (MP Biomedicals Inc., Irvin, CA, USA): $0.1 \mathrm{~mm}$ silica spheres, 4 times with 5 min break on ice, 6 $\mathrm{m} / \mathrm{s}, 10 \mathrm{~s}$ each. The extracts were then treated with ice-cold carbonate prior to protein solubilization using SDS. Protein content of the extracts was determined with the RC-DC assay (Bio-Rad GmbH, Munich, Germany) and $10 \mu \mathrm{g}$ total protein were separated using $12.5 \%$ acrylamide mini-gels. Following electrophoresis, gels were stained with Coomassie Brilliant Blue [Neuhoff et al., 1988] and each sample lane cut into 4 slices. Each slice was cut into small pieces $\left(\sim 1 \mathrm{~mm}^{2}\right)$ prior to washing, reduction, alkylation, and tryptic digest [Koßmehl et al., 2013]. Generated peptides were separated applying nano liquid chromatography (Ultimate 3000 nanoRSLC System; ThermoFisher Scientific, Germering, Bavaria, Germany) using a 2 -cm trap column $\left(\mathrm{C}_{18}, 5 \mu \mathrm{m}\right.$ bead size, $75 \mu \mathrm{m}$ inner diameter; ThermoFisher Scientific) coupled to a $25-\mathrm{cm}$ analytical column $\left(\mathrm{C}_{18}, 2 \mu \mathrm{m}\right.$ bead size, $75 \mu \mathrm{m}$ inner diameter; ThermoFisher Scientific) using a 90-min linear gradient [Wöhlbrand et al., 2016]. Eluting peptides were online ionized (CaptiveSpray ${ }^{\mathrm{TM}}$ ion source; Bruker Daltonik GmbH, Bremen, Germany) and mass analyzed by an ion trap (amaZon speed ETD; Bruker Daltonik $\mathrm{GmbH}$ ). Positive ions were analyzed with a capillary current of 1.3 $\mathrm{kV}$ and drygas flow of $3 \mathrm{~L} / \mathrm{min}$ nitrogen at $150^{\circ} \mathrm{C}$. Active precursor exclusion was set for $0.2 \mathrm{~min}$ and $20 \mathrm{MS} / \mathrm{MS}$ spectra per full scan MS acquired. Protein identification was performed by Mascot (version 2.3; Matrix Science Ltd., London, UK) operated via the ProteinScape platform (version 4.2; Bruker Daltonik GmbH). Search settings were as follows: significance threshold $p<0.05$; mass tolerance MS 0.3 Da, MS/MS 0.4 Da; false discovery rate $1.0 \%$ (applying target decoy); 1 missed cleavage site allowed; oxidation $\mathrm{M}$ variable modification; carbamidomethyl $\mathrm{C}$ fixed modification.

(ii) Shotgun Proteomics

Shotgun protein analysis covering cell disruption, removal of cell debris, reduction, alkylation, and tryptic in-solution digest was performed as described previously using 3 replicate samples per growth condition [Zech et al., 2013]. Obtained peptide mixtures were separated using a 240-min linear gradient [Wöhlbrand et al.,
2017] and protein identification performed as described above using compilation of replicate samples applying the protein extractor implemented in ProteinScape.

\section{Acknowledgements}

We are grateful to Jana Kalvelage for help with the proteomic work, Patrick Becker for bioinformatics, and Christoph Feenders for Matlab support (all Oldenburg).

\section{Statement of Ethics}

Ethical approval was not required for this type of study.

\section{Conflict of Interest Statement}

The authors have no conflicts of interest to declare.

\section{Funding Sources}

This study was supported within the framework of the $\mathrm{PhD}$ research training group "The Ecology of Molecules" (EcoMol) supported by the Lower Saxony Ministry for Science and Culture (MWK) and by the Max Planck Society.

\section{Author Contributions}

R.Ra conceived the study; V.S. manually annotated and analyzed both genomes and integrated the proteomic data; V.S. and L.W. performed data analyses and reconstructed the catabolic network; C.H. did the cultivation work; L.W., S.S., and C.H. conducted differential proteomics; R.Re determined the genomes of both Desulfonema strains; R.Ra wrote the manuscript with contributions from L.W. and V.S. All authors have agreed to the final version of the manuscript.

\section{References}

Aeckersberg F, Bak F, Widdel F. Anaerobic oxidation of saturated hydrocarbons to $\mathrm{CO}_{2}$ by a new type of sulfate-reducing bacterium. Arch Microbiol. 1991 Jul;156(1):5-14.

Amann J, Lange D, Schüler M, Rabus R. Substrate-dependent regulation of carbon catabolism in marine sulfate-reducing Desulfobacterium autotrophicum HRM2. J Mol Microbiol Biotechnol. 2010 Apr;18(2):74-84.

Arndt D, Grant JR, Marcu A, Sajed T, Pon A, Liang $\mathrm{Y}$, et al. PHASTER: a better, faster version of the PHAST phage search tool. Nucleic Acids Res. 2016 Jul;44(W1):W16-21.

Bairoch A, Apweiler R. The SWISS-PROT protein sequence database and its supplement
TrEMBL in 2000. Nucleic Acids Res. 2000 Jan; 28(1):45-8

Bland C, Ramsey TL, Sabree F, Lowe M, Brown K, Kyrpides NC, et al. CRISPR Recognition Tool (CRT): a tool for automatic detection of clustered regularly interspaced palindromic repeats. BMC Bioinformatics. 2007 Jun;8:209.

Boll M, Einsle O, Ermler U, Kroneck PMH, Ullmann GM. Structure and function of the unusual tungsten enzymes acetylene hydratase and class II benzoyl-coenzyme A reductase. J Mol Microbiol Biotechnol. 2016 Mar;26(1-3): 119-37.

Bowles MW, Mogollón JM, Kasten S, Zabel M, Hinrichs K-U. Global rates of marine sulfate reduction and implications for sub-sea-floor metabolic activities. Science. 2014 May; 344(6186):889-91.

Bury-Moné S, Nomane Y, Reymond N, Barbet R, Jacquet E, Imbeaud S, et al. Global analysis of extracytoplasmic stress signaling in Escherichia coli. PLoS Genet. 2009 Sep;5(9): e1000651.

Canfield DE, Jørgensen BB, Fossing H, Glud R, Gundersen J, Ramsing NB, et al. Pathways of organic carbon oxidation in three continental margin sediments. Mar Geol. 1993 Jul; 113(1-2):27-40.

Cypionka H. Oxygen respiration by Desulfovibrio species. Annu Rev Microbiol. 2000;54:827-48. 
Delcher AL, Harmon D, Kasif S, White O, Salzberg SL. Improved microbial gene identification with GLIMMER. Nucleic Acids Res. 1999 Dec;27(23):4636-41.

Devereux R, Delaney M, Widdel F, Stahl DA. Natural relationships among sulfate-reducing eubacteria. J Bacteriol. 1989 Dec;171(12):668995.

Dhillon BK, Laird MR, Shay JA, Winsor GL, Lo R, Nizam F, et al. IslandViewer 3: more flexible, interactive genomic island discovery, visualization and analysis. Nucleic Acids Res. 2015 Jul;43(W1):W104-8.

Dörries M, Wöhlbrand L, Kube M, Reinhardt R, Rabus R. Genome and catabolic subproteomes of the marine, nutritionally versatile, sulfate-reducing bacterium Desulfococcus multivorans DSM 2059. BMC Genomics. 2016a Nov;17:918.

Dörries M, Wöhlbrand L, Rabus R. Differential proteomic analysis of the metabolic network of the marine sulfate-reducer Desulfobacterium autotrophicum HRM2. Proteomics. 2016b Nov; 16(22):2878-93.

Elshahed MS, Senko JM, Najar FZ, Kenton SM, Roe BA, Dewers TA, et al. Bacterial diversity and sulfur cycling in a mesophilic sulfide-rich spring. Appl Environ Microbiol. 2003 Sept; 69(9):5609-21.

Fenchel TM, Jørgensen BB. Detritus foodchains in aquatic ecosystems: the role of bacteria. In: Alexander M, editor. Advances in Microbial Ecology. New York: Plenum Press; 1977. p. $1-58$.

Fourçans A, Ranchou-Peyruse A, Caumette P, Duran R. Molecular analysis of the spatiotemporal distribution of sulfate-reducing bacteria (SRB) in Camargue (France) hypersaline microbial mat. Microb Ecol. 2008 Jul; 56(1):90-100.

Fründ C, Cohen Y. Diurnal cycles of sulfate reduction under oxic conditions in cyanobacterial mats. Appl Environ Microbiol. 1992 Jan; 58(1):70-7.

Fukui M, Teske A, Aßmus B, Muyzer G, Widdel F. Physiology, phylogenetic relationships, and ecology of filamentous sulfate-reducing bacteria (genus Desulfonema). Arch Microbiol. 1999 Sep;172(4):193-203.

Galperin MY, Makarova KS, Wolf YI, Koonin EV. Expanded microbial genome coverage and improved protein family annotation in the COG database. Nucleic Acids Res. 2015 Jan; 443(D1):D261-9.

Gordon D. Viewing and editing assembled sequences using Consed. Curr Protoc Bioinformatics. 2003; Chapter 11.2.Unit11-2.

Guisbert E, Yura T, Rhodius VA, Gross CA. Convergence of molecular, modeling, and systems approaches for an understanding of the Escherichia coli heat shock response. Microbiol Mol Biol Rev. 2008 Sep;72(3):545-54.

Haeusser DP, Margolin W. Splitsville: structural and functional insights into the dynamic bacterial Z ring. Nat Rev Microbiol. 2016 May; 14(5):305-19.
Hai T, Lange D, Rabus R, Steinbüchel A. Polyhydroxyalkanoate (PHA) accumulation in sulfate-reducing bacteria and identification of a class III PHA synthase (PhaEC) in Desulfococcus multivorans. Appl Environ Microbiol. 2004 Aug;70(8):4440-8.

Hall TA. BioEdit: a user-friendly biological sequence alignment editor and analysis program for Windows 95/98/NT. Nucl Acids Symp Ser. 1999;41:95-8.

Heidelberg JF, Seshadri R, Haveman SA, Hemme CL, Paulsen IT, Kolonay JF, et al. The genome sequence of the anaerobic, sulfate-reducing bacterium Desulfovibrio vulgaris Hildenborough. Nat Biotechnol. 2004 May;22(5):554-9.

Horvath P, Barrangou R. CRISPR/Cas, the immune system of bacteria and archaea. Science. 2010 Jan;327(5962):167-70.

Huerta-Cepas J, Szklarczyk D, Heller D, Hernández-Plaza A, Forslund SK, Cook H, et al. eggNOG 5.0: a hierarchical, functionally and phylogenetically annotated orthology resource based on 5090 organisms and 2502 viruses. Nucleic Acids Res. 2019 Jan;47(D1): D309-14.

Jarrell KF, McBride MJ. The surprisingly diverse ways that prokaryotes move. Nat Rev Microbiol. 2008 Jun;6(6):466-76.

Jørgensen BB. Mineralization of organic matter in the sea bed - the role of sulfate reduction. $\mathrm{Na}-$ ture. 1982 Apr;296(5858):643-5.

Kempf B, Bremer E. Uptake and synthesis of compatible solutes as microbial stress responses to high-osmolality environments. Arch Microbiol. 1998 Sep;170(5):319-30.

Koßmehl S, Wöhlbrand L, Drüppel K, Feenders C, Blasius B, Rabus R. Subcellular protein localization (cell envelope) in Phaeobacter inhibens DSM 17395. Proteomics. 2013 Oct; 13(18-19):2743-60.

Krämer R. Bacterial stimulus perception and signal transduction: response to osmotic stress. Chem Rec. 2010 Aug;10(4):217-29.

Küever J. The family Desulfobacteraceae. In: Rosenberg E, DeLong EF, Lory S, Stackebrandt E, Thompson F, editors. The prokaryotes. Berlin, Heidelberg: Springer; 2014.

Kühn J, Briegel A, Mörschel E, Kahnt J, Leser K, Wick S, et al. Bactofilins, a ubiquitous class of cytoskeletal proteins mediating polar localization of a cell wall synthase in Caulobacter crescentus. EMBO J. 2010 Jan;29(2):327-39.

Lagesen K, Hallin P, Rødland EA, Stærfeldt H-H, Rognes T, Ussery DW. RNAmmer: consistent and rapid annotation of ribosomal RNA genes. Nucleic Acids Res. 2007 May;35(9): $3100-8$.

Lowe TM, Eddy SR. tRNAscan-SE: a program for improved detection of transfer RNA genes in genomic sequence. Nucleic Acids Res. 1997 Mar;25(5):955-64.

Lumppio HL, Shenvi NV, Summers AO, Voordouw G, Kurtz Jr DM. Rubrerythrin and rubredoxin oxidoreductase in Desulfovibrio vulgaris: a novel oxidative stress protection system. J Bacteriol. 2001 Jan;183(1):101-8.
Mahmoud SA, Chien P. Regulated proteolysis in bacteria. Annu Rev Biochem. 2018 Jun;87: 677-96.

Martin BC, Alarcon MS, Gleeson D, Middleton JA, Fraser MW, Ryan MH, et al. Root microbiomes as indicators of seagrass health. FEMS Microbiol Ecol. 2020 Feb;96(2):fiz201.

Minz D, Fishbain S, Green SJ, Muyzer G, Cohen Y, Rittmann BE, et al. Unexpected population distribution in a microbial mat community: sulfate-reducing bacteria localized to the highly oxic chemocline in contrast to a eukaryotic preference for anoxia. Appl Environ Microbiol. 1999 Oct;65(10):4659-65.

Mitchell AL, Attwood TK, Babbitt PC, Blum M, Bork P, Bridge A, et al. InterPro in 2019: improving coverage, classification and access to protein sequence annotations. Nucleic Acids Res. 2019 Jan;47(D1):D351-60.

Morbach S, Krämer R. Body shaping under water stress: osmosensing and osmoregulation of solute transport in bacteria. ChemBioChem. 2002 May;3(5):384-97.

Muyzer G, Stams AJM. The ecology and biotechnology of sulphate-reducing bacteria. Nat Rey Microbiol. 2008 June;6(6):441-54.

Neuhoff V, Arold N, Taube D, Ehrhardt W. Improved staining of proteins in polyacrylamide gels including isoelectric focusing gels with clear background at nanogram sensitivity using Coomassie Brilliant Blue G-250 and R-250. Electrophoresis. 1988 Jun;9(6):255-62.

Oliveira PH, Touchon M, Cury J, Rocha EPC. The chromosomal organization of horizontal gene transfer in bacteria. Nat Commun. 2017 Oct; $8(1): 841$

Phadtare S, Inouye M. The cold shock response. In: Slauch JM, editor. EcoSalPlus. ASM Press; 2008.

Rabus R, Kube M, Heider J, Beck A, Heitmann K, Widdel $\mathrm{F}$, et al. The genome sequence of an anaerobic aromatic-degrading denitrifying bacterium, strain EbN1. Arch Microbiol. 2005 Jan;183(1):27-36.

Rabus R, Nordhaus R, Ludwig W, Widdel F. Complete oxidation of toluene under strictly anoxic conditions by a new sulfate-reducing bacterium. Appl Environ Microbiol. 1993 May;59(5):1444-51.

Rabus R, Trautwein K, Wöhlbrand L. Towards habitat-oriented systems biology of "Aromatoleum aromaticum" EbN1. Chemical sensing, catabolic network modulation and growth control in anaerobic aromatic compound degradation. Appl Microbiol Biotechnol. 2014 Apr;98(8):3371-88.

Rabus R, Venceslau SS, Wöhlbrand L, Voordouw G, Wall JD, Pereira IAC. A post-genomic view of the ecophysiology, catabolism and biotechnological relevance of sulphate-reducing prokaryotes. Adv Microb Physiol. 2015;66:55321.

Ramm B, Heermann T, Schwille P. The E. coli MinCDE system in the regulation of protein patterns and gradients. Cell Mol Life Sci. 2019 Nov;76(21):4245-73. 
Revsbech NP, Jørgensen BB, Blackburn TH, Cohen Y. Microelectrode studies of the photosynthesis and $\mathrm{O}_{2}, \mathrm{H}_{2} \mathrm{~S}$, and $\mathrm{pH}$ profiles of a microbial mat. Limnol Oceanogr. 1983 Nov; 28(6):1062-74.

Rowley G, Spector M, Kormanec J, Roberts M. Pushing the envelope: extracytoplasmic stress responses in bacterial pathogens. Nature Rev Microbiol. 2006 May;4(5):383-94.

Rutherford K, Parkhill J, Crook J, Horsnell T, Rice P, Rajandream MA, et al. Artemis: sequence visualization and annotation. Bioinformatics. 2000 Oct;16(10):944-5.

Schauder R, Preuss A, Jetten M, Fuchs G. Oxidative and reductive acetyl-CoA/carbon monoxide dehydrogenase pathway in Desulfobacterium autotrophicum. 2. Demonstration of the enzymes of the pathway and comparison of CO dehydrogenase. Arch Microbiol. 1989 Dec;151(1):84-9.

Scheid D, Stubner S. Structure and diversity of Gram-negative sulfate-reducing bacteria on rice roots. FEMS Microbiol Ecol. 2001 Jul; 36(2-3):175-83.

Schneider S, Fuchs G. Phenylacetyl-CoA:acceptor oxidoreductase, a new a-oxidizing enzyme that produces phenylglyoxylate. Assay, membrane localization, and differential production in Thauera aromatica. Arch Microbiol. 1998 May;169(6):509-16.

Sigalevich P, Meshorer E, Helman Y, Cohen Y. Transition from anaerobic to aerobic growth conditions for the sulfate-reducing bacterium Desulfovibrio oxyclinae results in flocculation. Appl Environ Microbiol. 2000 Nov;66(11): 5005-12.

Spiess C, Beil A, Ehrmann M. A temperature-dependent switch from chaperone to protease in a widely conserved heat shock protein. Cell. 1999 Apr;97(3):339-47.

Strittmatter AW, Liesegang H, Rabus R, Decker I, Amann J, Andres S, et al. Genome sequence of Desulfobacterium autotrophicum HRM2, a marine sulfate reducer oxidizing organic carbon completely to carbon dioxide. Environ Microbiol. 2009 May;11(5):1038-55.
Teichmann L, Kümmel H, Warmbold B, Bremer E. OpuF, a new Bacillus compatible solute $\mathrm{ABC}$ transporter with a substrate-binding protein fused to the transmembrane domain. Appl Environ Microbiol. 2018 Oct;84(20): e01728-18.

Teske A, Jørgensen BB, Gallardo VA. Filamentous bacteria inhabiting the sheaths of marine Thioploca spp. on the Chilean continental shelf. FEMS Microbiol Ecol. 2009 May;68(2): 164-72.

Teske A, Ramsing NB, Habicht K, Fukui M, Küver J, Jørgensen BB, et al. Sulfate-reducing bacteria and their activities in cyanobacterial mats of Solar Lake (Sinai, Egypt). Appl Environ Microbiol. 1998 Aug;64(8):2943-51.

Trautwein K, Kühner S, Wöhlbrand L, Halder T, Kuchta K, Steinbüchel A, et al. Solvent stress response of the denitrifying bacterium "Aromatoleum aromaticum" strain EbN1. Appl Environ Microbiol. 2008 Apr;74(8):2267-74.

Trautwein K, Wilkes H, Rabus R. Proteogenomic evidence for $\beta$-oxidation of plant-derived 3 -phenylpropanoids in "Aromatoleum aromaticum" EbN1. Proteomics. 2012 May; 12(9):1402-13.

Vogt MS, Schühle K, Kölzer S, Peschke P, Chowdhury NP, Kleinsorge D, et al. Structural and functional characterization of an electron transfer flavoprotein involved in toluene degradation in strictly anaerobic bacteria. J Bacteriol. 2019 Nov;201(21):e00326-19.

Wagstaff J, Löwe J. Prokaryotic cytoskeletons: protein filaments organizing small cells. Nat Rev Microbiol. 2018 Apr;16(4):187-201.

Watanabe M, Kojima H, Umezawa K, Fukui M. Genomic characteristics of Desulfonema ishimotonii Tokyo $01^{\mathrm{T}}$ implying horizontal gene transfer among phylogenetically dispersed filamentous gliding bacteria. Front Microbiol. 2019 Feb;10:article227.

Widdel F. Methods for enrichment and pure culture isolation of filamentous gliding sulfatereducing bacteria. Arch Microbiol. 1983 Jul; 134(4):282-5.

Widdel F. Microbiology and ecology of sulphatereducing bacteria. In: Zehnder AJB, editor. Biology of Anaerobic Microorganisms. Munich: Carl Hanser Verlag Munich; 1988. p. 469-585.
Widdel F, Kohring G-W, Mayer F. Studies on dissimilatory sulfate-reducing bacteria that decompose fatty acids. III. Characterization of the filamentous gliding Desulfonema limicola gen. nov. sp. nov., and Desulfonema magnum sp. nov. Arch Micobiol. 1983 Jul;134(4):28694.

Wood JM. Bacterial osmoregulation: a paradigm for the study of cellular homeostasis. Annu Rev Microbiol. 2011;65:215-38.

Wong HL, Smith D-L, Visscher PT, Burns BP. Niche differentiation of bacterial communities at a millimeter scale in Shark Bay microbial mats. Sci Rep. 2015 Oct;5:15607.

Wöhlbrand L, Jacob JH, Kube M, Mussmann M, Jarling R, Beck A, et al. Complete genome, catabolic sub-proteomes and key-metabolites of Desulfobacula toluolica Tol2, a marine, aromatic compound-degrading, sulfate-reducing bacterium. Environ Microbiol. 2013 May; 15(5):1334-55.

Wöhlbrand L, Rabus R, Blasius B, Feenders C. Influence of nanoLC column and gradient length as well as MS/MS frequency and sample complexity on shotgun protein identification of marine bacteria. J Mol Microbiol Biotechnol. 2017 Sep;27(3):199-212.

Wöhlbrand L, Ruppersberg HS, Feenders C, Blasius B, Braun HP, Rabus R. Analysis of membrane-protein complexes of the marine sulfate reducer Desulfobacula toluolica Tol2 by $1 \mathrm{D}$ blue native-PAGE complexome profiling and $2 \mathrm{D}$ blue native-/SDS-PAGE. Proteomics. 2016 Mar; 16(6):973-88.

Zech H, Hensler M, Koßmehl S, Drüppel K, Wöhlbrand L, Trautwein K, et al. Adaptation of Phaeobacter inhibens DSM 17395 to growth with complex nutrients. Proteomics. 2013 Oct;13(18-19):2851-68.

Ziegler C, Bremer E, Krämer R. The BCCT family of carriers: from physiology to crystal structure. Mol Microbiol. 2010 Oct;78(1):13-34.

Zink KG, Rabus R. Stress-induced changes of phospholipids in betaproteobacterium Aromatoleum aromaticum strain EbN1 due to alkylbenzene growth substrates. J Mol Microbiol Biotechnol. 2010 Apr;18(2):92-101. 